pag

Business School

WORKING PAPER SERIES

Working Paper

2014-209
On the effects of world stock market and oil price shocks on food prices: An empirical investigation based on TVPVAR models with stochastic volatility

Ikram Jebabli

Mohamed Arouri

Frédéric Teulon

http://www.ipag.fr/fr/accueil/la-recherche/publications-WP.html

IPAG Business School

184, Boulevard Saint-Germain

75006 Paris

France 


\title{
On the effects of world stock market and oil price shocks on food prices: An \\ empirical investigation based on TVP-VAR models with stochastic volatility
}

\author{
Ikram Jebabli \\ CRCGM, Université d'Auvergne. \\ E-Mail:Ikram.Jebabli@udamail.fr \\ Mohamed Arouri \\ CRCGM-université d'Auvergne \\ E-Mail: Mohamed.arouri@gmail.com \\ Frédéric Teulon \\ IPAG Business School, IPAG - Lab, France \\ E-Mail:f.teulon@ipag.fr
}

\begin{abstract}
Transmission of price shocks from one market to another one has long been investigated in the economic literature. However, studies have namely dealt with the relationship between financial and energy markets. With the recent changes in market conditions, investors, policy-makers and interest groups are giving special attention to food market. This paper aims at analyzing shocks transmission between international food, energy and financial markets and to provide some insights into the volatility behavior during the past years and discuss its implications for portfolio management. To do this, we present a new Time Varying Parameter VAR model (TVP-VAR) with stochastic volatility approach which provides extreme flexibility with a parsimonious specification. We resort also to a generalized vector autoregressive framework in which forecast-error variance decompositions are invariant to the variable ordering for the assessment of total and directional volatility spillovers. Our main findings suggest that there is volatility spillover from crude oil and international stock markets to food markets. Shocks to crude oil or $\mathrm{MSCl}$ markets have immediate and short-term impacts on food markets which are emphasized during the financial crisis period. Moreover, we show that augmenting a diversified portfolio of food commodities with crude oil or stocks significantly increases its risk-adjusted performance.
\end{abstract}

Keywords: Price volatility, TVP-VAR model, stochastic volatility, total volatility spillovers, directional volatility spillovers, food market, energy market, financial market, portfolios diversification, hedge effectiveness. 


\section{Introduction}

During the 2000s, world indexes related to food prices and energy prices have shown simultaneous upward trends and volatilities. Figure 1 below, which represents the evolution over time of these two indexes provided from International Monetary Fund (IMF) database, illustrates this trend. This has led to think about shock and volatility transmission mechanisms between these two markets.

\section{Please insert Figure 1 about here}

This topic has become a central issue for the global economy and has been widely discussed mainly since the financial crisis due to the significant rise in energy and food prices. Nevertheless, there is still less agreement about the causal factors of this shock and volatility transmission. It has been raised in the literature that volatility of agricultural commodities is no longer simply guided by rules of the fundamental factors related to supply and demand (Prakash and Gilbert, 2011). Different sources can explain this volatility which may be summed up in natural shocks related to climatic changes, stock levels, agricultural product demand and supply, growing links with energy and financial markets, and macroeconomic factors (exchange rates and interest rates).

It is evident that understanding volatility transmission mechanisms is essential for both international investors and policy makers (Mensi et al., 2013). In fact, as commodity markets are increasingly viewed as alternative investment areas, existence and direction of spillovers must be carefully evaluated by investors. Investors need this type of information for the purpose of their portfolio risk management in order to develop their investment strategies for each market and to decide whether they can benefit from risk diversification. It is argued that food commodities are having as much interest in portfolio allocation as crude oil prices have (Gilbert, 2010).

Policy makers also require this information about volatility to settle on the appropriate policy namely by establishing the accurate pricing models and also to anticipate future actions and decisions (Deaton, 1999). Numerous studies have focused on commodity price stabilization policies that have to be carried out by governments. Most of these have dealt 
with agricultural prices (Wright, 2001). In their works, Gardner (1979) and Gouel (2013) have generalized the scope to deal with food prices. According to Gouel (2013), it is essential to identify the precise economic motives for intervention and to design the policies accordingly given the pervasiveness of these policies and the potential cost of food price spikes for poor consumers. Many international organizations have investigated policy responses in order to manage food price volatility (Gilbert, 2012). Recommendations issued form these organizations ${ }^{1}$ have been formulated in the 2011 G20 Summit on food security.

Special attention has been actually devoted to the source of food volatility related to the link between energy and financial markets. In a report from the Global Development and Environment Institute and the Institute for Agriculture and Trade Policy, Wise and Murphy (2012) have illustrated the paradigm shift between agriculture, energy and financial markets and mentioned that this paradigm is caused by the deepening integration of the three markets.

Recent empirical studies have analyzed the determinants of volatility in food commodity prices by resorting to different econometric methods and focusing on different data during various periods of time. These studies reveal a divergence between the findings obtained which makes this issue a topic of current discussions.

In fact, most of these studies highlight the significant volatility linkages between oil prices and most food commodities prices which is deepened through biofuel sector growth (among others: Baffes, 2007; Akram, 2009; Balcombe, 2011; Ciaian and Kancs, 2011; Busse et al., 2011). These studies agree on the fact that oil price volatility translates into food price volatility through two key elements. The first one corresponds to transportation costs and fertilizer prices. The second element is related to biofuels and the expanding use of agricultural commodities as feedstocks for biofuel production. This agreement, taken alone, leads to think that transmission of oil price volatilities to crop prices may be more rapid.

The work of Baffes (2007) has been based both on food price indices and individual food prices annual data for the 1960-2005 period analyzed through an Ordinary Least Squares regression. Akram (2009) findings, obtained from structural VAR models, have been based on a larger sample covering the period 1990-2007 with data having a higher frequency

\footnotetext{
${ }^{1}$ FAO, OECD, IFAD, IMF, UNCTAD, WFP, the World Bank, the WTO, IFPRI, and the UN HLT.
} 
(quarterly data) corresponding to real commodity prices. Balcombe (2011) analyzed monthly and annual prices during the period 1957-2009 covering various food commodities (wheat, maize, rice, soybean, rapeseed, palm, poultry, beef, pigmeat, butter, cheese, cocoa, coffee, tea, sugar and cotton) through random parameters models with time varying volatility and a panel regression approach. A much larger sample has been used by Ciaian and Kancs (2011) covering the period 1993-2010. This sample is composed of price series having a much higher frequency (weekly data) and corresponding to a wider variety of foods (corn, wheat, rice, sugar, soybeans, cotton, banana, sorghum and tea). The work of Ciaian and Kancs (2011) has been characterized by the consideration of the structural breaks while studying price transmission between energy, bioenergy and food prices. For this purpose, Ciaian and Kancs (2011) divided the sample into three periods (1993-1998, 1999-2004 and 20052010). The first one is characterized by the reduction in the OPEC spare capacity. The second period is related to the increase in bioenergy policy support in developed economies. The third one corresponds to the significant expansion of biofuel production. An analysis focusing on daily rapeseed future prices from 1999 to 2009 has been done by Busse et al. (2011) using Dynamic Conditional Correlation method.

Some other works indicate that volatility spillover form crude oil to food commodities prices is not always significant. For instance, we can cite the works of Du et al. (2011) and Nazlioglu et al. (2013). Du et al. (2011) findings indicate volatility spillover among crude oil, corn and wheat markets after the fall of 2006. Data considered by Du et al. (2011) correspond to futures prices weekly observed from 1998 to 2009. These data have been analyzed by applying stochastic volatility models and resorting to Bayesian econometric analysis for the estimation of the models' parameters. The same result has been shared by Nazlioglu et al. (2013) by extending the scope of agricultural commodities considered (wheat, corn, soybeans, and sugar) and raising their frequency to daily prices observed over a longer sample from 01 January 1986 to 21 March 2011. Nazlioglu et al. (2013) apply a different method which corresponds to the causality in variance test and impulse response functions. In order to identify the impact of the food price crisis, Nazlioglu et al. (2013) divided the data into two sub-periods: the pre-crisis period (January 1986-31 December 2005) and the postcrisis period (01 January 2006-21 March 2011). Their findings mention that, with the 
exception of sugar, volatility spillover between oil and agricultural markets is absent in the pre-crisis period and is confirmed during the post-crisis period.

Nevertheless, some other studies reveal no volatility spillover effect between these two markets (among others: Zhang et al., 2010; Kaltalioglu and Soytas, 2011). The results of Zhang et al. (2010) indicate no direct long-run price relations between fuel and agricultural commodity prices and limited if any direct short-run relationships, except for sugar which has an influence on increasing agricultural commodity prices through biofuel production affects. These results, obtained by means of cointegration estimation and a vector error corrections model, are based on monthly price data of fuels (ethanol, gasoline and oil) and agricultural commodities (corn, rice, soybeans, sugar and wheat) for the period 1989-2008. Kaltalioglu and Soytas (2011) have extended the sample to include, in addition to agricultural commodities, other food commodities. Their sample is composed of price indexes for the period from 1980 to 2008 observed monthly and covering fruits, vegetables, meat, poultry, fish, grocery food, and non-alcoholic beverages. For the purpose of volatility spillover investigation, they based their analysis on the Granger causality in variance approach developed by Cheung and $\mathrm{Ng}$ (1996).

Therefore, the literature review highlights Zilberman et al. (2013) statement which consists on the fact that the relationship between fuels and food commodities prices depends, among others, on commodities considered for each one of these two markets, the specification of the models used for this finality and the frequency of considered data.

Concerning volatility transmission between financial and food markets, most of the previous works have considered the S\&P 500 index. We can list hereafter, as summary and not exhaustive review, some of the recent relevant work that has been done. Mensi et al. (2013) investigate the return links and volatility transmission between S\&P 500 and commodity price indices for energy, food, gold and beverages over the period from 2000 to 2011 by resorting to a VAR-GARCH model. Their findings indicate a significant volatility transmission among commodity markets and the S\&P 500. Creti et al. (2013) findings confirm this by means of the dynamic conditional correlation GARCH methodology applied to data observed during the period 2001-2011 covering, among other commodities, energy, agricultural, food, oleaginous, exotic and livestock commodities. Creti et al. (2013) also highlight the role 
played by the 2007-2008 financial crisis in emphasizing the links between commodities and stock market and the financialization of commodity markets.

The recent work of Chen et al. (2013) identifies two common factors which are responsible for changes in international commodity prices. This work is based on a factor analysis procedure (Panel Analysis of Nonstationarity in Idiosyncratic and Common Components) developed by Bai and $\mathrm{Ng}$ (2004) which is applied to a panel of 51 international commodity prices, including non-fuel commodity indices, food index, beverage index, and agricultural raw material index, from January 1980 to December 2009. The results provide strong evidence that the most important common factor that drives the persistent movement of international commodity prices corresponds to US nominal exchange rate. The second common factor shows stable fluctuations which may be consistent with stationarity and may be closely related to some economic conditions such as the excess demand for certain commodities. The works conducted by Roache (2010) and Gilbert (1989) emphasize that commodity prices can be influenced by exchange rates via international purchasing power and the effects on margins for producers with non-American dollar costs.

In this paper, we focus on volatility transmission between crude oil prices, $\mathrm{MSCl}$ index prices and a large panel of food commodities prices differing in terms of their production topology (crops, livestock products, plantation and forestry products). We explore also whether $\mathrm{MSCl}$ index and crude oil prices have a role in driving food prices. To the extent of our knowledge, we focus here for the first time on real prices of livestock products and $\mathrm{MSCl}$ stock index market. We resort in our analysis to a Time Varying Parameter VAR model (TVP-VAR) with stochastic volatility which allows to take into account the economy structure evolution and the volatility of the shocks. Total and directional volatility spillovers are assessed based on a generalized vector autoregressive framework in which forecast-error variance decompositions are invariant to the variable ordering.

The remaining of this paper evolves as follows. Next section introduces the methodology adopted in this paper. The following one presents the characteristics of our data and a preliminary analysis of these data. The penultimate section discusses empirical findings related to total and directional volatility spillovers, impulse responses and portfolio diversification. The last one concludes and points to some directions for future research. 


\section{Methodology}

Most of the methods used in the literature in order to analyze commodity prices volatility are based on GARCH models which allow for rich insights into the volatility structure of time series and provide information about the conditional correlation between the changes of different price series in their multivariate versions. However, GARCH models do not offer a clear unified methodology to uncover volatility dynamics operating between the involved variables and to recognize structural changes. Multivariate $\mathrm{GARCH}$ models share the main problem which consists on the difficulty, in many cases, to obtain convergence of the optimization algorithms used to estimate the parameters.

Since there are similarities between GARCH and VAR models, we generalize VAR models to allow for stochastic time-varying volatilities and extend impulse response functions to the analysis of shocks in volatility. Compared to previous works discussed above, this article provides a new look at the transmission of shocks between food, financial and energy markets and provide original findings on the impact of independent shock on volatility. This choice has been based on the studies of Primiceri (2005) and Koop et al. (2009) which mention that both the transmission mechanism and the variance of the exogenous shocks have changed over time. Koop and Korobilis (2010) also highlight that the issue of the appropriate modeling of the error covariance matrix in multivariate time series models has led to the incorporation of multivariate stochastic volatility in many empirical papers. Hence, understanding the macroeconomic policy issues should be based on multivariate models where both the VAR coefficients and the error covariance matrix can potentially change over time. This reflects both time variation of the simultaneous relations among the variables of the model and heteroskedasticity of the innovations.

More precisely, we build on the multivariate time-varying parameter vector autoregressive (TVP-VAR) model introduced recently by Primiceri (2005) and especially used in analyzing macroeconomic issues for the empirical research of price volatility behavior. The TVP-VAR model has an advantage over the constant parameter VAR models in the sense that it does not need to divide data into subsamples to confirm the change of the structure of the model (Jouchi Nakajima et al., 2009). Thus, we avoid the risk of losing information based on the entire sample and having results which depend on the arbitrary choice of the sub-samples. In fact, instead of splitting the sample into several sub-samples, the time variation in the 
parameters enables the exact dating of the transition. The time-varying variances capture the change in the impact and nature of the shocks, enabling us to model the apparent decline in volatility.

The standard VAR model with constant parameters allows drawing impulse responses only for a set of two variables under the assumption that parameters do not change over the horizon of the impulse responses. With the TVP-VAR model, an additional dimension corresponding to time can be added which permits to check responses at different points in time. As we will explain below, this major advantage of the TVP-VAR model family is very useful to investigate transmission of volatility shocks between different markets.

In order to be able to capture possible changes in underlying structure of the considered markets in a flexible and robust manner, we build on Omori et al. (2007) and extend the TVP-VAR model of Primiceri (2005) by incorporating stochastic volatility. Thus, our model allows to reflect both time variation of the simultaneous relations among the variables which can be due to variations in the structural dynamic interrelations among macroeconomic variables and heteroskedasticity of the innovations which can be due to changes in the size of exogenous shocks or their impact on macroeconomic variables (D’Agostino et al., 2013).

According to Primiceri (2005), Omori et al. (2007) and Jouchi (2011), the TVP-VAR model is constructed form the basic structural VAR model by allowing the parameters to change over time. We consider a basic structural VAR model defined as:

$$
A y_{t}=F_{1} y_{t-1}+\cdots+F_{s} y_{t-s}+u_{t}, \quad t=s+1, \ldots, n
$$

where :

$$
\left\{\begin{array}{c}
y_{t} \text { is } a k \times 1 \text { vector of observed variables } \\
A, F_{1}, \ldots, F_{s} \text { are } k \times k \text { matrices of coefficients } \\
u_{t} \text { is } a k \times 1 \text { structural shock with } u_{t} \sim N(0, \Sigma \Sigma)
\end{array}\right.
$$

$$
\Sigma=\left(\begin{array}{cccc}
\sigma_{1} & 0 & \cdots & 0 \\
0 & \ddots & \ddots & \vdots \\
\vdots & \ddots & \ddots & 0 \\
0 & \cdots & 0 & \sigma_{k}
\end{array}\right)
$$




$$
A=\left(\begin{array}{cccc}
1 & 0 & \ldots & 0 \\
a_{21} & \ddots & \ddots & \vdots \\
\vdots & \ddots & \ddots & 0 \\
a_{k 1} & \ldots & a_{k, k-1} & 1
\end{array}\right)
$$

The reduced form of this model can be written as follows:

$$
\begin{aligned}
& y_{t}=B_{1} y_{t-1}+\cdots+B_{s} y_{t-s}+A^{-1} \sum \varepsilon_{t}, \quad \varepsilon_{t} \sim N\left(0, I_{k}\right) \\
& \text { Where } B_{i}=A^{-1} F_{i}, \quad i=1, \ldots, s
\end{aligned}
$$

This form can be written in this way:

$$
y_{t}=X_{t} \beta+A^{-1} \sum \varepsilon_{t}
$$

With:

$$
\left\{\begin{array}{c}
\beta \text { is a }\left(k^{2} s \times 1\right) \text { vector obtained by stacking the elements in the rows of the } B_{i}{ }^{\prime} s \\
\qquad X_{t}=I_{s} \otimes\left(y^{\prime}{ }_{t-1}, \ldots, y^{\prime}{ }_{t-s}\right)
\end{array}\right.
$$

The expression of this model to the TVP-VAR model with stochastic volatility is given by:

$$
y_{t}=X_{t} \beta_{t}+A_{t}^{-1} \sum_{t} \varepsilon_{t}, t=s+1, \ldots, n
$$

For simplicity, a number of assumptions are done for the specification of the TVP-VAR model $^{2}$. First, the matrix $A_{t}$ is assumed to be a lower-triangular matrix. Second, the parameters are supposed to follow a random walk process as follows:

$$
\left\{\begin{array}{l}
\beta_{t+1}=\beta_{t}+u_{\beta t} \\
a_{t+1}=a_{t}+u_{a t} \\
h_{t+1}=h_{t}+u_{h t}
\end{array}\right.
$$

with:

$h_{t}=\left(h_{1 t}, \ldots, h_{k t}\right)^{\prime}$ where $h_{k t}=\log \sigma_{j t}^{2}, j=1, \ldots, k, t=s+1, \ldots, n$

$\beta_{s+1} \sim N\left(\mu_{\beta_{0}}, \sum_{\beta_{0}}\right)$

\footnotetext{
${ }^{2}$ For a discussion of these assumptions, please see Christiano et al. (1999).
} 
$a_{s+1} \sim N\left(\mu_{a_{0}}, \sum_{a_{0}}\right)$

$h_{s+1} \sim N\left(\mu_{h_{0}}, \sum_{h_{0}}\right)$

The variance covariance matrix of the model's innovations is block diagonal.

$$
\left(\begin{array}{c}
\varepsilon_{t} \\
u_{\beta t} \\
u_{a t} \\
u_{h t}
\end{array}\right) \sim N\left(0,\left(\begin{array}{cccc}
1 & 0 & 0 & 0 \\
0 & \sum_{\beta} & 0 & 0 \\
0 & 0 & \sum_{a} & 0 \\
0 & 0 & 0 & \sum_{h}
\end{array}\right)\right)
$$

Where $\sum_{a}$ and $\sum_{h}$ are assumed to be diagonal matrixes.

The assumption of random walk process allows for both temporary and permanent shifts in the coefficients. In this specification, possible non linearity such as a gradual change or a structural break can be estimated.

TVP regression forms the state space model for which different estimation methods have been developed. In case of constant volatility, the standard Kalman filter for a Gaussian state space model is used. This method is heavy to implement in case of stochastic volatility since the model forms a non-linear state space model. As stated by Koop and Korobilis (2010), macroeconomists are facing the challenge of the choice of models which allow representing key data features and in the same time are not over-parameterized. It is argued that shrinkage enables to resolve the over-parameterization issue. Thereby, the recourse to Bayesian methods use has increased since priors constitute a way of introducing this shrinkage. Therefore, Bayesian inference will be introduced as an alternative to overcome the over-parameterization problem.

In this paper, we resort to Markov Chain Monte Carlo (MCMC) method which is appropriate for several reasons. The first reason corresponds to the intractability of the likelihood function because the model includes the nonlinear state equations of stochastic volatility. The second is the opportunity offered by this method to make the inference for the state variables with the uncertainty of the unknown parameters. This method allows also estimating the function of the parameters such as an impulse response function with the uncertainty of the unknown parameters. As stated by Primiceri (2004) and Copy (2011), MCMC method delivers smoothed estimates of the parameters of interest based on the 
entire available set of data. These estimates are more efficient than the filtered estimates in case of interest in the evolution of the unobservable states over time, which is the case for the issues we address in this paper.

We thereby start by setting in advance certain prior probability densities similarly to Primiceri (2005). For a discussion about the different methods for the settlement of the priors, we refer to the work by Koop and Korobilis (2010). Based on these priors, we assess through MCMC algorithm the joint posterior distributions of the parameters of interest.

The MCMC algorithm involves the following steps:

1. Initialize $\beta, a, h$ and $w$

2. Sample $\beta$ from $p\left(\beta \mid a, h, \sum_{\beta}, \mathrm{y}\right)$

3. Sample $\sum_{\beta}$ from $p\left(\sum_{\beta} \mid \beta\right)$

4. Sample $a$ from $p\left(a \mid \beta, h, \sum_{a}, \mathrm{y}\right)$

5. Sample $\sum_{a}$ from $p\left(\sum_{a} \mid \mathrm{a}\right)$

6. Sample $h$ from $p\left(h \mid \beta, a, \sum_{h}, \mathrm{y}\right)$

7. Sample $\sum_{h}$ from $p\left(\sum_{h} \mid \mathrm{h}\right)$

8. Go back to 2

In order to generate the VAR parameters $\beta$, we use the equations below :

$$
\left\{\begin{array}{c}
y_{t}=X_{t} \beta_{t}+A_{t}^{-1} \sum_{t} \varepsilon_{t}, t=s+1, \ldots, n \\
\beta_{t+1}=\beta_{t}+u_{\beta t}, \quad t=s, \ldots, n-1 \\
\text { where } \beta_{s}=\mu_{\beta_{0}} \text { and } \mu_{\beta_{s}} \sim N\left(0, \sum_{\beta_{0}}\right)
\end{array}\right.
$$

Simulation smoother introduced by de Jong and Shephard (1995), Durbin and Koopman (2002) is employed to speed the convergence of the Markov chain.

To sample the covariance states $a$, we use the equations below to implement the simulation smoother:

$$
\left\{\begin{array}{c}
\hat{y}_{t}=\hat{X}_{t} a_{t}+\sum_{t} \varepsilon_{t}, \quad t=s+1, \ldots, n \\
a_{t+1}=a_{t}+u_{a t}, \quad t=s, \ldots, n-1
\end{array}\right.
$$




$$
\begin{gathered}
\text { where } a_{s}=\mu_{a_{0}}, \mu_{a_{s}} \sim N\left(0, \sum_{a_{0}}\right) \\
\hat{y}_{t}=y_{t}-X_{t} \beta_{t}
\end{gathered}
$$

and for $t=s+1, \ldots, n$ :

$$
\hat{X}_{t}=\left(\begin{array}{cccccccc}
0 & \ldots & & & & & & 0 \\
-\hat{y}_{1 t} & 0 & 0 & \ldots & & & & \vdots \\
0 & -\hat{y}_{1 t} & -\hat{y}_{2 t} & 0 & \ldots & & & \\
0 & 0 & 0 & -\hat{y}_{1 t} & \ldots & & & \\
\vdots & & & & \ddots & 0 & \ldots & 0 \\
0 & \ldots & & & 0 & -\hat{y}_{1 t} & \ldots & -\hat{y}_{k-1, t}
\end{array}\right)
$$

In order to draw stochastic volatility states $h$, we make the inference for $\left\{h_{j t}\right\}_{t=s+1}^{n}$ separately for $j=1, \ldots, k$.

The $i$-th element of $A_{t} \hat{y}_{t}$ can be written us :

$$
\begin{gathered}
y_{i t}^{*}=\exp \left(\frac{h_{i t}}{2}\right) \varepsilon_{i t}, t=s+1, \ldots, n \\
h_{i, t+1}=h_{i t}+\eta_{i t}, t=s, \ldots, n-1 \\
\left(\begin{array}{l}
\varepsilon_{i t} \\
\eta_{i t}
\end{array}\right) \sim N\left(0,\left(\begin{array}{cc}
1 & 0 \\
0 & v_{i}^{2}
\end{array}\right)\right)
\end{gathered}
$$

Where:

$\eta_{i s} \sim N\left(0, v_{i 0}^{2}\right), v_{i}^{2}$ the $i$-th diagonal elements of $\sum_{h}, v_{i 0}^{2}$ the $i$-th diagonal elements of $\sum_{h 0}$ and $\eta_{i t}$ the $i$-th element of $u_{h t}$.

To sample $\left(h_{i, s+1}, \ldots, h_{i, n}\right)$, the multi-move sampler is used (Shephard and Pitt (1997) and Watanabe and Omori (2004).

\section{Data and preliminary analysis}

To study volatility shocks transmission between food, energy and financial markets, we consider, based on Deaton (1999) and Baffes (2007) recommendation, series of the individual commodities prices rather than price indices. Thus, we avoid the aggregation bias 
of commodity prices and the weighting rule to combine them into indices (Hadri et al., 2013).

All these prices are expressed in American dollar and cover a long period of more than three decades (1980-2012) on a monthly basis. Food and energy prices are obtained from the International Monetary Fund (IMF). Food commodities covered by these data are different in terms of production topology: crops (Maize, Barley and Rapeseed oil), livestock products (lamb, beef and fish), and plantation and forestry products (Banana, Cocoa beans and Ground nuts). This large panel of different type of commodities will give us the opportunity to check whether they constitute a homogeneous asset class in the matter of their links with energy and stock markets. For the energy market, we consider in this paper crude oil. A brief description of the indicator price of these commodities is given in Appendix 1. As for the financial market, we consider the $\mathrm{MSCl}$ world stock market index for the same period obtained from Morgan Stanley Capital International (MSCl) company database.

Figure 2 in Appendix 2 presents commodity prices and $\mathrm{MSCl}$ stock market index during our sample period. Similar to financial time series, commodities prices exhibit time varying volatility (volatility clustering) and fat tails as mentioned in the distribution of returns presented in Figure 1 in Appendix 2.

A visual inspection of price evolutions suggests links between food, energy and stock markets. Especially, a strong increase in commodities prices emerged until 2008 financial crisis. To better understand market dynamics that affect food commodities, their interrelationships, and their link to crude oil and $\mathrm{MSCl}$ index, an analysis of volatility is required.

We test, in a first time, the stationarity properties of our series using the augmented DickeyFuller (ADF) test where the alternative hypothesis is stationary. ADF test reveals, as mentioned in table 1 below, non stationarity in prices where the null hypothesis of the existence of a unit root cannot be rejected for any series. However, the returns series show stationarity at $10 \%$ significance level, implying they are integrated of order 1. 
According to the AIC, FPE, HQ and the SC criterion, the optimal lag number is $p=1$. Residuals are found to be white noise when the lag length is set to 1 . Diagnostic plots of $\operatorname{VAR}(1)$ are not produced in this paper for brevity. Thus, we estimate the VAR, Structural Vector Autoregression (SVAR) and TVP-VAR models based on one lag length.

\section{Empirical results}

In this section, we consider each time a three-variable TVP-VAR model in order to assess volatility transmission between energy, financial and food markets and check if the magnitude of the impacts varies over time. Price returns are used to ensure stationary.

The estimation of the parameters of the TVP-VAR model requires that priors be fixed in advance. Taking account of our data, we assume the following priors:

$$
\left\{\begin{array}{l}
\sum_{\beta} \sim I W(80,0.01 I) \\
\left(\sum_{a}\right)_{i}^{-2} \sim G(4,0.02) \\
\left(\sum_{h}\right)_{i}^{-2} \sim G(4,0.02)
\end{array}\right.
$$

Where $\left(\sum_{a}\right)_{i}^{-2}$ and $\left(\sum_{h}\right)_{i}^{-2}$ the i-th diagonal elements in $\sum_{a}$ and $\sum_{h}$ respectively, $I W$ and $G$ denote the inverse Wishart and the Gamma distributions respectively.

Table 2 below presents the estimation results computed using MCMC algorithm (posterior means, standard deviations, 95\% credible intervals, Geweke convergence diagnostics statistics and inefficiency). Based on Geweke statistics, the null hypothesis of the convergence to the posterior distribution in the estimated result is not rejected for the parameters of the TVP-VAR model at the $5 \%$ significance level. In addition, the inefficiency factors are quite low and the $95 \%$ confidence intervals include the estimated posterior mean for each of the parameters estimated. Therefore, the results show that posterior draws are efficiently produced by the MCMC algorithm. Figure 4 in Appendix 2 presents the estimation results of the TVP-VAR model with stochastic volatility. 
As stated before, TVP-VAR model will allow us to assess effects at different time periods. Hence, this will avoid us to estimate for each significant time period a model (Alom et al. 2011).

\subsection{Stochastic volatility estimation}

Figure 2 below presents the dynamics of the estimated stochastic volatilities of commodity price returns series over time $\sigma_{i t}^{2}=\exp \left(h_{i t}\right)$ based on the posterior mean and $95 \%$ credible intervals. This figure shows that volatility varies significantly in the time which reinforces the use of the TVP-VAR model with stochastic volatility to avoid biased estimation since posterior estimates of stochastic volatilities are significant. This observation confirms the evidence introduced in the literature on the topic of this point.

Three key important dates for stochastic volatilities of most of the food series are observed (1980, 1990 and 2008) and cyclical ups and downs are detected. These observations are in line in particular with those of Stock and Waston (2002) who qualify the 1980 period as the Great Moderation period, Koop and Korobilis (2010), Ciaiana and Kancs (2011) and Creti et al. (2013). As stated by Creti et al. (2013), the relatively increase in food volatility during the 2007-2008 financial crisis reveals the phenomenon of commodity markets financialization.

We observe that stochastic volatility of most of food series has over some sub-periods similar evolutions as the $\mathrm{MSCl}$ and crude oil. In fact, often when high volatilities are observed for $\mathrm{MSCl}$ index and crude oil prices, volatilities in food commodities returns are observed, but with different magnitude. This observation suggests that there is volatility transmission from $\mathrm{MSCl}$ and crude oil to food commodities. Our approach allows to test for that.

Figure 2 also illustrates that agricultural products are more volatile than livestock products. This can be explained by the fact that production in agriculture takes time, so the supply cannot respond much to price changes in the short term, unless stocks are available.

Please insert Figure 2 about here 


\subsection{Impulse responses estimation}

Impulse responses for the TVP-VAR model are computed by fixing an initial shock size equal to the time-series average of stochastic volatility for each commodity over the whole sample period and then using the simultaneous relations at each point in time. Hence, time-varying volatility contributes to the VAR estimation, identifying the structural shock with the appropriate variance of the shock size. The

The simultaneous relations of the structural shock are presented in figure 4 in Appendix 2 . Posterior means and \pm 1 standard deviation confidence intervals show that the simultaneous relations of the structural shock are not significantly time varying in all cases.

Figures from 1 to 9 in Appendix 4 show the impulse responses for food commodities price returns following a shock on crude oil price returns and $\mathrm{MSCl}$ stock index price returns obtained from the constant parameter VAR model, SVAR model and the TVP-VAR model. Time varying responses to shocks for 3 months, 6 months and one year horizon are presented ${ }^{3}$. Horizontal axes indicate the number of months after shock and vertical axes represent the standardized responses to shocks for each variable. It is clear that there is significant variation of the impulse responses over time which supports applying the TVPVAR model.

The results illustrated through these figures emphasize those of Deaton (1999) and Baffes (2007) regarding the adoption of individual commodities prices instead of indexes. In fact, although there are some common features between the different food commodities, some differences issued from particularities of each food can be detected among them. This is in accordance with Creti et al. (2013) findings that agree on the fact that the different types of commodities cannot be aggregated in a homogeneous asset class (Creti et al., 2013).

General finding observed for all food commodities can be stressed. The first one corresponds to the immediately of the impact of a shock, either of crude oil returns or $\mathrm{MSCl}$ index returns, on food returns and its low amplitude. This impact is a short term one since it is absorbed within a period of six months. Our results support in part namely those of Nazlioglu et al. (2013) which show that the responses of a selection of agricultural

\footnotetext{
${ }^{3}$ The red, purple and green lines respectively in charts of posterior means correspond to these time horizons.
} 
commodity prices (wheat, corn, soybeans, and sugar) to oil prices shocks are immediate and not permanent (they are absorbed in about a month). This lack of returns persistence to a shock indicates a rapid market response mitigating a shock's effect. Such a response supports the theory indicating decentralized perfectly competitive markets are efficient in responding to price signals (Zhang et al., 2010).

Mainly two important dates have been identified for most of food commodities during which the impact on food commodities returns of either crude oil or $\mathrm{MSCl}$ index returns shocks is stressed. The first one is related to the great moderation period (the beginning of the 1980s). The second one corresponds to the financial crisis (2008 year) which highlights the phenomenon of food commodities financialization. Increases on the impact of crude oil shocks in most of food commodities in 2008 year are also explained by the significant expansion of biofuel production. These findings are in line with most of previous works, in particular those of Ciaiana and Kancs (2011).

For all food commodities, it is shown that the impacts of shocks can be biased if assessed through VAR model with constant parameters and constant volatility. The large 95\% confidence intervals show that impulse responses obtained by applying constant VAR and SVAR models are not significant in all cases. Hence, the assumption of constant parameters over the horizon of the impulse responses induced by constant VAR model biased the results. This observation outlines the importance of considering a VAR model with time varying parameters and stochastic volatility.

The implementation of the TVP-VAR model with stochastic volatility has allowed the identification of structural shocks with the appropriate variance of shocks' size. This is illustrated through the amplitude of the impacts which is more significant once evaluated based on TVP-VAR model with stochastic volatility. Hence, the recourse to the TVP-VAR model with stochastic volatility has allowed us to avoid the misspecification of the dynamics of VAR model parameters.

\subsection{Volatility spillovers estimation}

In order to assess volatility spillovers, we follow the approach adopted by Diebold and Yilmaz (2012) based on a generalized vector autoregressive framework in which forecast-error variance decompositions are invariant to the variable ordering. This approach allows 
measuring both the total and directional volatility spillovers (from/to a particular market). Table 3 below presents volatility spillover tables.

\section{Please insert Table 3 about here}

For each table, the $\mathrm{ij}$ th entry represents the estimated contribution to the forecast error variance of market $\mathrm{i}$ coming from innovations to market $\mathrm{j}$. It is clear from this table that both the total and directional volatility spillovers are low. The directional to others rows of the volatility spillover table show that gross directional volatility spillovers are comparable. The directional from others columns of the volatility spillover table show that gross directional volatility spillovers from other markets are not very different. The directional volatility spillovers from crude oil to foods range between 0.01 (for Banana) and 1.44 (for Lamb). Those from MSCl to foods are between 0.23 (for Cocoa Beans) and 3.23 (for Barley and Fish). The total volatility spillover, which is a distillation of the various directional volatility spillovers into a single index, indicates that, on average, a percentage comprised between $1.35 \%$ and $2.85 \%$ of the volatility forecast error variance in all three markets comes from spillovers.

Our results confirm the findings in the literature stating that oil prices have been mentioned as an additional shock to food price via supply and demand channels (Thompson et al. 2009). In fact, an increase in oil prices results in an increase in input costs (like fertilizers, irrigation, and transportation) and an increase in demand for grains as biofuels having as a consequence an increase in food commodity prices.

As mentioned above, results found through assessing only one single index for the full sample period indicate low total and directional spillovers. However, the application of this approach to markets which are volatile over time probably can lead to not considering potentially important cyclical movements in spillovers. We propose then to assess dynamic volatility spillovers over different time intervals through applying a rolling window approach. To do this, we estimate volatility spillovers using one month rolling sample.

Our results for the total (non directional) volatility spillovers index over time presented in figure 1 in Appendix 3 allow measuring the contribution of spillovers of volatility shocks 
across the three types of asset classes to the total forecast error variance. This figure shows that the total volatility spillover plot mostly fluctuates between $10 \%$ and $40 \%$ for each one of the sets considered composed each time of 3 types of assets (Oil, Food and MSCl stock). Several cycles can be identified namely in 1980, 1990 and the most important one corresponds to the financial crisis period (2007-2009).

In order to take into account directional information, we estimate directional volatility spillovers from others and directional spillovers to others indexes using one month rolling windows approach.

Directional volatility spillovers to each one of the assets coming from other assets are presented in figure 2 in Appendix 3. These spillovers vary obviously over time. Directional volatility spillovers to foods and oil markets are increasing in turbulent times relatively more than those to $\mathrm{MSCl}$ stocks.

Figure 3 in Appendix 3 shows the directional volatility spillovers from each one of the assets (corresponding to energy, food and stocks markets) to others. These spillovers vary greatly over time. This figure also indicates that volatility spillovers from food and energy markets are smaller than those from stock markets.

In order to consider the difference between volatility shocks transmitted from market $\mathrm{i}$ to market $\mathrm{j}$ and those transmitted from market $\mathrm{j}$ to $\mathrm{i}$, we estimate the net pairwise volatility spillovers between these two markets. Figure 4 in appendix 3 shows these net pairwise volatility spillovers. Most of the time in our sample, the net pairwise volatility spillovers from $\mathrm{MSCl}$ stock to foods are positive and those from crude oil to foods are negative. Net pairwise volatility spillovers show that volatility from $\mathrm{MSCl}$ stock and crude oil markets are transmitted to all types of foods with similar ranges varying mostly between $-20 \%$ and $20 \%$.

\subsection{Implications for portfolios diversification}

Based on the fact that the benefits of diversification are most appreciated when risk market rises and investors tend to choose commodities as refuge instruments, we propose in this part to study the implications of food commodities' sensitivity to oil and $\mathrm{MSCl}$ shocks on decisions taken by the investors regarding the risk management of their portfolios. We consider two hedged portfolios. The first one is a hedged portfolio of crude oil and food commodities. The second one is a hedged portfolio of $\mathrm{MSCl}$ and food commodities. 
To determine the optimal weights of the portfolios and hedging ratios, we use the results issued from our TVP-VAR model on the subject of the Variance-Covariance matrix. We base our work on Kroner and $\mathrm{Ng}$ (1998) regarding the optimal weight of holding food commodities in a portfolio constructed of either crude oil or $\mathrm{MSCl}$ at time $t$. In their work, Arouri et al. (2011) adopt the same approach in order to analyze the optimal weights and hedge ratios for oil-stock portfolio holdings.

We consider the following equation for the optimal weight of a portfolio composed of food and crude oil.

$$
w_{t}^{\text {oil,Food }}=\frac{h_{t}^{\text {Oil }}-h_{t}^{\text {Oil,Food }}}{h_{t}^{\text {Food }}-2 h_{t}^{\text {Oil,Food }}+h_{t}^{\text {Oil }}}
$$

on condition:

$$
w_{t}^{\text {Oil }, \text { Food }}=\left\{\begin{array}{c}
0 \text { if } w_{t}^{\text {Oil,Food }}<0 \\
w_{t}^{\text {Oil }, \text { Food }} \text { if } 0 \leq w_{t}^{\text {Oil }, \text { Food }} \leq 1 \\
1 \text { if } w_{t}^{\text {Oil,Food }}>1
\end{array}\right.
$$

where:

$$
\left\{\begin{array}{c}
h_{t}^{\text {Oil }}: \text { conditional volatility of crude oil at time } t \\
h_{t}^{\text {Food }}: \text { conditional volatility of food at time } t \\
h_{t}^{\text {Oil,Food }}: \text { conditional covariance between } \\
\text { crude oil and food at time } t
\end{array}\right.
$$

The weight of food commodities in a portfolio constituted of food commodities and crude oil is equal to $1-w_{t}^{\text {Oil,Food }}$.

The risk minimizing the hedge ratios for the portfolio composed of crude oil and food commodities, following Kroner and Sultan (1993) work, is considered as:

$$
\beta_{t}^{\text {Oil,Food }}=\frac{h_{t}^{\text {Oil,Food }}}{h_{t}^{\text {Food }}}
$$

The same thing is applied for the portfolio composed of food and $\mathrm{MSCl}$ stock assets. 


$$
\begin{gathered}
w_{t}^{\text {MSCI,Food }}=\frac{h_{t}^{M S C I}-h_{t}^{\text {MSCI,Food }}}{h_{t}^{\text {Food }}-2 h_{t}^{M S C I, F o o d}+h_{t}^{M S C I}} \\
\beta_{t}^{\text {MSCI,Food }}=\frac{h_{t}^{\text {MSCI,Food }}}{h_{t}^{\text {Food }}}
\end{gathered}
$$

Figures from 1 to 9 in Appendix 5 show the time-varying optimal hedge ratios. These hedge ratios are not stable and have large fluctuations, requiring the hedgers to frequently adjust their futures positions. In the table 4 below, we summarize the average values obtained regarding the optimal portfolios weights and hedge ratios along time.

Please insert Table 4 about here

As shown in table 4, the hedge ratios are typically low, suggesting that hedging effectiveness involving food and crude oil or food and stocks is quite good. They underline the fact that oil and stock assets should be an integral part of a diversified portfolio of food. Thus, inclusion of crude oil or stocks in a diversified portfolio of food commodities increases the riskadjusted performance of the resulting portfolio.

In a $1 \$$ portfolio of crude oil and food, the optimal weights range from 17,6\% (Banana) to $71,1 \%$ (Beef). It means that for a $1 \$$ portfolio of crude oil and Banana, 17,6 cents should be invested in crude oil and the remainder ( 82,4 cents) should be invested in Banana. However in a $1 \$$ portfolio of crude oil and Beef, the majority of the investment has to be done in crude oil (71,1 cents). Table 4 shows also that the optimal portfolios weights for a portfolio composed of crude oil and food are comparable for each type of food, except for the plantation and forestry products where the investment in Banana is much more important than for Cocoa Beans and Ground nuts.

In a $1 \$$ portfolio of stocks and food, the optimal weights are comprised between $8,7 \%$ (Banana) and $59,4 \%$ (Beef). It is also notable, when comparing the optimum weights of the two portfolios that investors have to invest more in crude oil than in stocks. We notice also a similarity of the estimates of the optimal portfolios weights into each category of food, except for the Banana. 
Hedge ratios are negative for the portfolios composed of crude oil and Maize, crude oil and Banana, stocks and Banana, and stocks and Cocoa Beans. This reflects the fact that spot and futures prices may move in opposite direction in short run (Tong, 1996). It requires the hedger to go long in futures market to hedge the long spot position.

In order to check the effectiveness of the portfolio diversification, we study the realized hedging errors determined by Ku et al. (2007).

$$
H E=\left(\frac{\text { Var }_{\text {unhedged }}-V a r_{\text {hedged }}}{\text { Var }}\right)
$$

where:

$$
\left\{\begin{array}{c}
\text { Var hedged } \text { variance of the returns on the Oil - Food } \\
\text { or MSCI - Food portfolios } \\
\text { Var }_{\text {unhedged }}: \text { variance of the returns on the Oil } \\
\text { or MSCI portfolios }
\end{array}\right.
$$

We use for the allocation of each portfolio the optimum weights previously determined.

Table 5 below summarizes the results obtained for these hedge ratios.

A higher HE ratio indicates greater hedging effectiveness in terms of the portfolio's variance reduction, which thus implies that the associated investment method can be deemed a better hedging strategy.

\section{Please insert Table 5 about here}

The highest hedge effectiveness ratio obtained for a portfolio composed of (Crude oil, Crops) is reached with the introduction of Maize (56\%). Thus, we can say that Maize provides the most useful risk management tool for hedging and for portfolio diversification among the crops considered in this paper. Hedge effectiveness for portfolios composed of $(\mathrm{MSCl}$, Livestock products) are comparable and high (from $70,9 \%$ to $81,8 \%$ ). This indicates that introduction of Livestock products into a portfolio of Crude oil allows to significantly improve its risk return characteristics. Negative estimated hedge effectiveness have been found for 
the (Crude oil, Banana) portfolio and for almost all the ( $\mathrm{MSCl}$, Food) portfolios. This may be because of higher futures return variance.

\section{Conclusion}

This paper highlights that the time-varying volatility contributes to the VAR estimation since it allows identifying the structural shock with the appropriate variance of the shock size. Therefore, the adoption of a TVP-VAR model where the sources of time variation are both the coefficients and the variance covariance matrix of the innovations has allowed us to avoid biased estimation of the parameters. A general finding from this paper points to the fact that, although there are some common features between the different food commodities, some differences issued from particularities of each food can be detected among them.

The findings identify the presence of low volatility spillover from crude oil or $\mathrm{MSCl}$ returns to most of food returns. Hence, policy makers and investors can forecast food prices and their volatilities through the information about crude oil or $\mathrm{MSCl}$ index. In terms of shocks' transmission from crude oil or $\mathrm{MSCl}$ to food commodities, impulse responses show that the impact of these shocks is immediate and a short run one since it is absorbed within a six months period. This indicates a rapid market response mitigating a shock's effect. The results highlight also the key role played by the 2007-2008 financial crisis in emphasizing shocks' transmission from crude oil or stock markets to foods.

Net pairwise volatility spillovers show that most of time, and for all types of foods, volatilities spillover positively from $\mathrm{MSCl}$ stock to foods and negatively from crude oil to foods with similar ranges varying between $-20 \%$ and $20 \%$. Understanding shocks transmission and volatility spillovers among the different markets provides investors with useful information which can be considered in their decisions related to optimal portfolio allocation.

Regarding the diversification of portfolios, hedge ratios are found to be not stable and have large fluctuations, requiring the hedger to frequently adjust their futures positions. The mean values indicate typically low hedge ratios, suggesting that hedging effectiveness involving food and crude oil or food and stocks is quite good. Thus, inclusion of crude oil or 
stocks in a diversified portfolio of food commodities increases the risk-adjusted performance of the resulting portfolio. An extension to this work could be through the adoption of large TVP-VAR models or TVP-FAVAR (Factor Augmented VAR) models. To put forward on this work, a study of prices transmission between different food commodities and cross countries can be achieved. The present work can also be extended in order to discuss about the different drivers of food commodity prices which can be summarized on market-specific factors, broad macroeconomic determinants, speculative components, and weather variables and in order to quantify their impact. 


\section{References}

[1] Akram, 2009. Commodity prices, interest rates and the dollar. Energy Economics, 31, 838-851.

[2] Alom, F., Ward, B., Hu, B., 2011. Spillover effects of World oil prices on food prices: evidence for Asia and Pacific countries. In Proceedings of the 52nd Annual Conference New Zealand Association of Economists, 29 June -1 July 2011. Wellington. New Zealand Association of Economists.

[3] Arouri, H., Jouini, J., Nguyen, D., 2011. Volatility spillovers between oil prices and stock sector returns: Implications for portfolio management. Journal of International Money and Finance, 30, 1387-1405.

[4] Baffes, J., 2007. Oil spills on other commodities. Resources Policy, 32, 126-134.

[5] Bai and Ng, 2004. A PANIC attack on unit roots and cointegration. Econometrica, 72, 1127-1177.

[6] Balcombe K., 2011. The nature and determinants of volatility in agricultural prices: an empirical study, FAO 2011.

[7] Blind Copy, 2011. A Time-Varying Structural VAR Model to Estimate the effects of Changes in Fiscal Policy, working paper.

[8] Chen, S., Jackson, J., Kim, H., Resiandini, P., 2013. What Drives Commodity Prices?, Auburn Economics Working Paper Series auwp2013-03, Department of Economics, Auburn University.

[9] Christiano, L. J., M. Eichenbaum, and C. L. Evans (1999). Monetary policy shocks: What have we learned and to what end? In J. B. Taylor and M. Woodford (Eds.), Handbook of Macroeconomics, 3, 65-148. Amsterdam: Elsevier Science B. V.

[10] Ciaian, P., Kancs, d'., 2011. Food, energy and environment: Is bioenergy the missing link? Food Policy, 36, 571-580.

[11] Creti, A., Joëts, M., Mignon, V., 2013. On the links between stock and commodity markets' volatility. Energy Economics, 37, 16-28.

[12] D’Agostino, A., Gambetti, L., Giannone, D., 2013. Macroeconomic forecasting and structural change. Journal of Applied Econometrics, 28, 82-101.

[13] Deaton, A., 1999. Commodity prices and growth in Africa. Journal of Economic Perspectives, 13, 23-40.

[14] de Jong, P. and N. Shephard (1995). The simulation smoother for time series models. Biometrika, $82,339-350$.

[15] Diebold, F., Yilmaz, K., 2012. Better to give than to receive: Predictive directional measurement of volatility spillovers. International Journal of Forecasting, 28, 57-66.

[16] Du, X., Yu, C. Hayes, D., 2011. Speculation and volatility spillover in the crude oil and agricultural commodity markets: A Bayesian analysis. Energy Economics, 33, 497-503.

[17] Durbin, J. and S. J. Koopman (2002). Simple and efficient simulation smoother for state space time series analysis. Biometrika, 89, 603-616. 
[18] Gardner, B.L., 1979. Robust stabilization policies for international commodity agreements. The American Economic Review, 69, 169-172. Papers and Proceedings of the 91st Annual Meeting of the American Economic Association.

[19] Gilbert, C. L., 1989. The Impact of Exchange Rate Changes and Developing Country Debt on Commodity Prices, Economic Journal, 99(397), 773-784.

[20] Gilbert, C. L. 2010. How to understand high food prices. Journal of Agricultural Economics, 61, 398-425.

[21] Gilbert, C. L. 2012. International agreements to manage food price volatility. Global Food Security, 1, 134-142.

[22] Gouel, C., 2013. Optimal food price stabilisation policy. European Economic Review, 57, 118134.

[23] Grilli, E., Yang, M.C., 1988. Primary commodity prices, manufactured goods prices, and the terms of trade of developing countries: What the long run shows. The World Bank Economic Review, 2, 147.

[24] Hadri, K., Arezki, R., Rao, Y., Loungani, P., 2013. Breaking the Dynamic of Relative Primary Commodity Prices in Levels and Volatilities since 1650. International Conference organized by the IMF's Research Department and the Oxford Centre for the Analysis of Resource Rich Economies at Oxford University.

[25] James, S., Watson, M., 2002. Has the business cycle changed and why? NBER Macroeconomics Annual.

[26] Jouchi Nakajima, 2011. Time-Varying Parameter VAR Model with Stochastic Volatility: An Overview of Methodology and Empirical Applications, IMES discussion paper series, Discussion Paper No. 2011-E-9.

[27] Kaltalioglu, M., Soytas U., 2011. Volatility Spillover from Oil to Food and Agricultural Raw Material Markets, Modern Economy, 2, 71-76.

[28] Koop, G., Leon-Gonzalez, R. and Strachan, R., 2009. On the evolution of the monetary policy transmission mechanism. Journal of Economic Dynamics and Control, 33, 997-1017.

[29] Koop, G., Korobilis, D., 2010. Bayesian multivariate time series methods for empirical macroeconomics. Foundations and trends in Econometrics, 3, 267-358.

[30] Kroner, K.F., Sultan, J., 1993. Time-varying distributions and dynamic hedging with foreign currency futures. Journal of Financial and Quantitative Analysis, 28, 535-551.

[31] Kroner, K.F., Ng, V.K., 1998. Modeling asymmetric movements of asset prices. Review of Financial Studies, 11, 844-871.

[32] Ku, Y.H., Chen, H., Chen, K., 2007. On the application of the dynamic conditional correlation model in estimating optimal timevarying hedge ratios. Applied Economics Letters, 7, 503-509.

[33] Mensi et al., 2013. Correlations and volatility spillovers across commodity and stock markets : Linking energies, food, and gold. Economic Modelling, 32, 15-22. 
[34] Nakajima, J., M. Kasuya, and T. Watanabe (2011). Bayesian analysis of time-varying parameter vector autoregressive model for the Japanese economy and monetary policy. Journal of the Japanese and International Economies, 25, 225-245.

[35] Nazlioglu, S., Erdem, C., Soytas, U., 2013. Volatility spillover between oil and agricultural commodity markets. Energy Economics, 36, 658-665.

[36] Ng, S., 2006. Testing cross-section correlation in panel data using spacings. Journal of Business and Economic Statistics, 24, 12-23.

[37] Omori Y., S. Chib, N. Shephard and J. Nakajima (2007). Stochastic volatility with leverage: Fast likelihood inference. Journal of Econometrics, 140, 425-449.

[38] Prakash, A., Gilbert, C., 2011. Rising vulnerability in the global food system: beyond market fundamentals, FAO 2011.

[39] Primiceri, G. E., 2005. Time varying structural vector autoregressions and monetary policy. Review of Economic Studies, 72, 821-852.

[40] Roache, S., 2010. What Explains the Rise in Food Price Volatility? IMF Working Paper, No. 10/129.

[41] Shephard, N. and M. Pitt (1997). Likelihood analysis of non-Gaussian measurement time series. Biometrika, 84, 653-667.

[42] S. Pfaffenzeller, P. Newbold, A. Rayner, 2007. A short note on updating the Grilli and Yang Commodity Price Index. The World Bank Economic Review, 2, 151-163.

[43] Stefan Busse, Bernhard Brümmeret Rico Ihle, 2011. Merging linkages between price volatilities in energy and agricultural markets, FAO 2011.

[44] Thompson, W., Meyer, S., Westhoff, P., 2009. How does petroleum price and corn yield volatility affect ethanol markets with and without an ethanol use mandate? Energy Policy, 37, 745-749.

[45] Toda, H.Y., Yamamoto, T., 1995. Statistical inference in vector autoregression with possibly integrated processes. Journal of Econometrics, 66, 225-250.

[46] Tong, W. H. S. (1996). An examination of dynamic hedging. Journal of International Money and Finance, 15, 19-35.

[47] Watanabe, T. and Y. Omori, 2004. A multi-move sampler for estimating non-Gaussian time series models: comments on Shephard and Pitt (1997). Biometrika, 91, 246-248.

[48] Wise, T., and Murphy, S., 2012. Resolving the Food Crisis: Assessing Global Policy Reforms Since 2007. Report from the Global Development and Environment Institute and the Institute for Agriculture and Trade Policy.

[49] Y. Cheung and L. K. Ng, 1996. A causality-in-Variance test and its application to financial market prices. Journal of Econometrics, 72, 33-48.

[50] Zhang, Z., Lohr, L., Escalante, C., \& Wetzstein, M., 2010. Food versus fuel: What do pricestell us? Energy Policy, 38, 445-451.

[51] Zilberma, D., et al., 2013. The impact of biofuels on commodity food prices: Assessment of findings. American Journal of Agricultural Economics, 95, 275-281. 


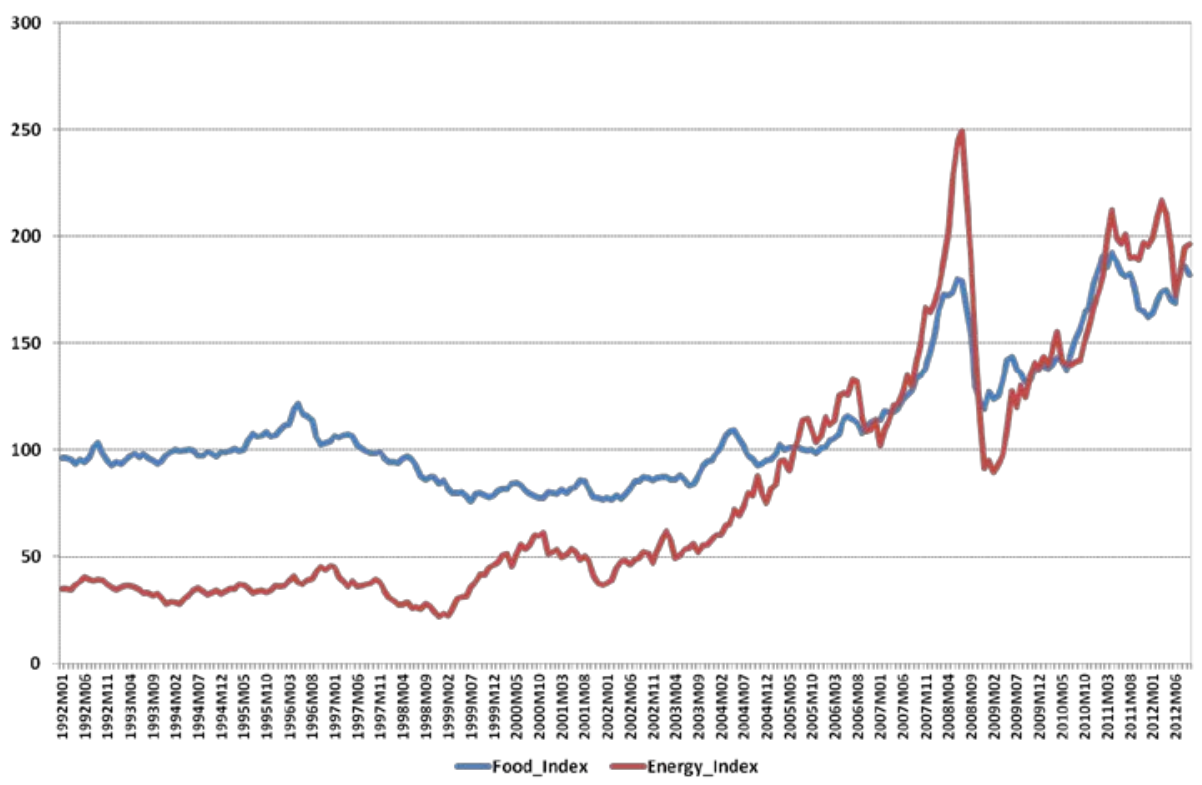

Food_Index : Food Price Index, $2005=100$, includes Cereal, Vegetable Oils, Meat, Seafood, Sugar, Bananas and Oranges Price Indices

Energy_Index : Fuel (Energy) Index, $2005=100$, includes Crude oil, Natural Gas and Coal Price Indices

Figure 1: Evolution of food and energy price indexes 


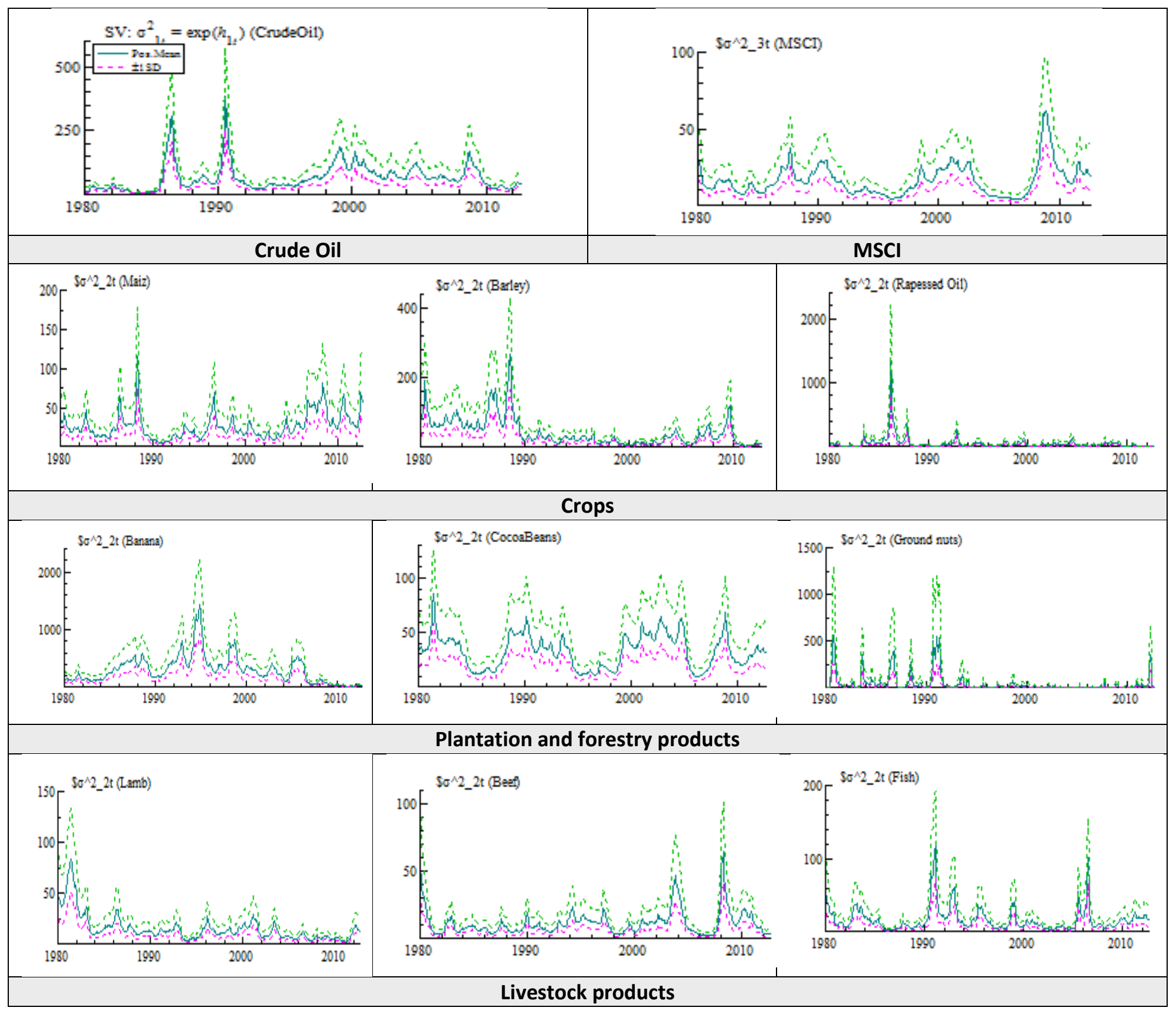

Figure 2: Posterior estimates of stochastic volatility of structural shock 
Table 1: Augmented Dickey-Fuller Test

\begin{tabular}{|l|c|c|c|c|}
\hline \multirow{2}{*}{} & \multicolumn{2}{|c|}{ Prices } & \multicolumn{2}{c|}{ Returns } \\
\cline { 2 - 5 } & p-value & Test statistic & p-value & Test statistic \\
\hline Banana & 0.160 & -2.988 & 0.01 & -11.139 \\
Barley & 0.441 & -2.323 & 0.01 & -6.804 \\
CocoaBeans & 0.986 & -0.395 & 0.01 & -7.999 \\
Rapeseed Oil & 0.519 & -2.137 & 0.01 & -7.095 \\
Fish & 0.069 & -3.309 & 0.01 & -6.829 \\
Ground Nuts & 0.625 & -1.887 & 0.01 & -6.379 \\
Lamb & 0.120 & -3.082 & 0.01 & -7.590 \\
Maize & 0.272 & -2.723 & 0.01 & -6.938 \\
Crude Oil & 0.765 & -1.554 & 0.01 & -7.798 \\
MSCl & 0.788 & -1.500 & 0.01 & -8.486 \\
\hline
\end{tabular}


Table 2: Estimation results of selected parameters in the TVP-VAR model

\begin{tabular}{ccccccc}
\hline Parameter & Mean & Stdev & 95\%L & \multicolumn{3}{c}{ 95\%U Gewekelnef. } \\
\hline$\left(\sum_{\beta}\right)_{1}$ & 0.0045 & 0.0003 & 0.0039 & 0.0052 & 0.036 & 11.20 \\
$\left(\sum_{\beta}\right)_{2}$ & 0.0046 & 0.0003 & 0.0040 & 0.0053 & 0.607 & 11.88 \\
$\left(\sum_{a}\right)_{1}$ & 0.0498 & 0.0101 & 0.0334 & 0.0723 & 0.595 & 88.92 \\
$\left(\sum_{a}\right)_{2}$ & 0.0518 & 0.0103 & 0.0349 & 0.0753 & 0.372 & 52.11 \\
$\left(\sum_{h}\right)_{1}$ & 0.3963 & 0.0601 & 0.2940 & 0.5286 & 0.800 & 35.33 \\
$\left(\sum_{h}\right)_{2}$ & 0.4186 & 0.0825 & 0.2797 & 0.6044 & 0.240 & 70.45 \\
\hline
\end{tabular}

(a) Estimates for the set (Crude Oil, Maize, MSCl)

\begin{tabular}{ccccccc}
\hline Parameter & Mean & Stdev & 95\%L & \multicolumn{3}{c}{ 95\%U Gewekelnef. } \\
\hline$\left(\sum_{\beta}\right)_{1}$ & 0.0045 & 0.0003 & 0.0039 & 0.0052 & 0.032 & 5.85 \\
$\left(\sum_{\beta}\right)_{2}$ & 0.0045 & 0.0003 & 0.0039 & 0.0052 & 0.678 & 7.21 \\
$\left(\sum_{a}\right)_{1}$ & 0.0573 & 0.0130 & 0.0368 & 0.0863 & 0.406 & 84.96 \\
$\left(\sum_{a}\right)_{2}$ & 0.0515 & 0.0105 & 0.0347 & 0.0763 & 0.001 & 65.15 \\
$\left(\sum_{h}\right)_{1}$ & 0.3962 & 0.0571 & 0.2921 & 0.5195 & 0.141 & 36.60 \\
$\left(\sum_{h}\right)_{2}$ & 0.4545 & 0.0791 & 0.3135 & 0.6246 & 0.450 & 48.93 \\
\hline
\end{tabular}

(b) Estimates for the set (Crude Oil, Barley, MSCl)

\begin{tabular}{ccccccc}
\hline Parameter & Mean & Stdev & 95\%L & 95\%U & Gewekelnef. \\
\hline$\left(\sum_{\beta}\right)_{1}$ & 0.0045 & 0.0003 & 0.0039 & 0.0052 & 0.454 & 8.58 \\
$\left(\sum_{\beta}\right)_{2}$ & 0.0045 & 0.0003 & 0.0039 & 0.0052 & 0.871 & 7.92 \\
$\left(\sum_{a}\right)_{1}$ & 0.0526 & 0.0115 & 0.0345 & 0.0785 & 0.116 & 65.75 \\
$\left(\sum_{a}\right)_{2}$ & 0.0490 & 0.0100 & 0.0333 & 0.0730 & 0.979 & 53.06 \\
$\left(\sum_{h}\right)_{1}$ & 0.3905 & 0.0594 & 0.2827 & 0.5182 & 0.407 & 49.36 \\
$\left(\sum_{h}\right)_{2}$ & 0.3068 & 0.0584 & 0.2095 & 0.4373 & 0.000 & 69.22 \\
\hline
\end{tabular}

(c) Estimates for the set (Crude Oil, Cocoa Beans, MSCl)

\begin{tabular}{cllllll}
\hline Parameter & Mean & Stdev & 95\%L & \multicolumn{2}{c}{ 95\%U Gewekelnef. } \\
\hline$\left(\sum_{\beta}\right)_{1}$ & 0.0045 & 0.0003 & 0.0039 & 0.0052 & 0.339 & 6.36 \\
$\left(\sum_{\beta}\right)_{2}$ & 0.0045 & 0.0003 & 0.0039 & 0.0052 & 0.001 & 6.60 \\
$\left(\sum_{a}\right)_{1}$ & 0.0412 & 0.0071 & 0.0297 & 0.0573 & 0.389 & 52.80 \\
$\left(\sum_{a}\right)_{2}$ & 0.0482 & 0.0099 & 0.0327 & 0.0723 & 0.824 & 72.07 \\
$\left(\sum_{h}\right)_{1}$ & 0.3902 & 0.0548 & 0.2898 & 0.5091 & 0.061 & 27.98 \\
$\left(\sum_{h}\right)_{2}$ & 0.4210 & 0.0665 & 0.3020 & 0.5616 & 0.610 & 39.48 \\
\hline
\end{tabular}

(d) Estimates for the set (Crude Oil, Beef, MSCl)

\begin{tabular}{ccccccc}
\hline Parameter & Mean & Stdev & 95\%L & 95\%U & Gewekelnef. \\
\hline$\left(\sum_{\beta}\right)_{1}$ & 0.0045 & 0.0003 & 0.0039 & 0.0052 & 0.561 & 8.49 \\
$\left(\sum_{\beta}\right)_{2}$ & 0.0045 & 0.0003 & 0.0039 & 0.0052 & 0.000 & 12.56 \\
$\left(\sum_{a}\right)_{1}$ & 0.0441 & 0.0080 & 0.0304 & 0.0614 & 0.000 & 51.03 \\
$\left(\sum_{a}\right)_{2}$ & 0.0515 & 0.0115 & 0.0336 & 0.0783 & 0.001 & 52.07 \\
$\left(\sum_{h}\right)_{1}$ & 0.3892 & 0.0550 & 0.2881 & 0.5031 & 0.001 & 29.20 \\
$\left(\sum_{h}\right)_{2}$ & 0.5122 & 0.0847 & 0.3639 & 0.7040 & 0.740 & 45.58 \\
\hline
\end{tabular}

(e) Estimates for the set (Crude Oil, Fish, MSCl) 


\begin{tabular}{ccccccc}
\hline Parameter & Mean & Stdev & 95\%L & \multicolumn{2}{c}{ 95\%U } & Gewekelnef. \\
\hline$\left(\sum_{\beta}\right)_{1}$ & 0.0045 & 0.0003 & 0.0039 & 0.0052 & 0.992 & 11.52 \\
$\left(\sum_{\beta}\right)_{2}$ & 0.0045 & 0.0003 & 0.0039 & 0.0052 & 0.568 & 5.00 \\
$\left(\sum_{a}\right)_{1}$ & 0.0482 & 0.0097 & 0.0335 & 0.0714 & 0.924 & 48.79 \\
$\left(\sum_{a}\right)_{2}$ & 0.0497 & 0.0108 & 0.0338 & 0.0765 & 0.944 & 67.62 \\
$\left(\sum_{h}\right)_{1}$ & 0.4056 & 0.0581 & 0.2978 & 0.5278 & 0.974 & 27.61 \\
$\left(\sum_{h}\right)_{2}$ & 0.6282 & 0.0814 & 0.4771 & 0.7963 & 0.629 & 23.61 \\
\hline
\end{tabular}

(f) Crude Oil, Rapeseed Oil, MSCl

\begin{tabular}{ccccccc}
\hline Parameter & Mean & Stdev & 95\%L & 95\%U Gewekelnef. \\
\hline$\left(\sum_{\beta}\right)_{1}$ & 0.0045 & 0.0003 & 0.0039 & 0.0052 & 0.535 & 6.67 \\
$\left(\sum_{\beta}\right)_{2}$ & 0.0045 & 0.0003 & 0.0039 & 0.0052 & 0.050 & 8.74 \\
$\left(\sum_{a}\right)_{1}$ & 0.0430 & 0.0075 & 0.0307 & 0.0598 & 0.522 & 54.53 \\
$\left(\sum_{a}\right)_{2}$ & 0.0514 & 0.0104 & 0.0347 & 0.0747 & 0.536 & 69.62 \\
$\left(\sum_{h}\right)_{1}$ & 0.3881 & 0.0577 & 0.2862 & 0.5136 & 0.750 & 42.87 \\
$\left(\sum_{h}\right)_{2}$ & 1.0828 & 0.1108 & 0.8801 & 1.3112 & 0.472 & 42.18 \\
\hline
\end{tabular}

(g) Crude Oil, Ground Nuts, MSCl

(Mean : posterior means, Stdev : standard deviations, 95\%L : 95\% Lower credible interval limit, 95\%U : 95\% Upper credible interval limit, Geweke : Geweke convergence diagnostics statistics, Inef : inefficiency) 
Table 3: Volatility spillover tables

\begin{tabular}{|c|c|c|c|c|}
\hline & $\mathrm{MSCl}$ & Maize & Crude Oil & $\begin{array}{c}\text { Directional form } \\
\text { others }\end{array}$ \\
\hline MSCl & 99.41 & 0.014 & 0.57 & 0.584 \\
\hline Maize & 1.85 & 97.47 & 0.67 & 2.52 \\
\hline Crude Oil & 2.00 & 0.13 & 97.87 & 2,13 \\
\hline Directional to others & 3.85 & 0.14 & 1.24 & \\
\hline \multirow[t]{2}{*}{ Directional including own } & 103.26 & 97.61 & 99.11 & $\begin{array}{c}\text { Total spillover } \\
\text { index } 1.74 \%\end{array}$ \\
\hline & $\mathrm{MSCl}$ & Barley & Crude Oil & $\begin{array}{c}\text { Directional form } \\
\text { others }\end{array}$ \\
\hline MSCl & 99.22 & 0.29 & 0.49 & 0.78 \\
\hline Barley & 3.23 & 95.91 & 0.87 & 4.1 \\
\hline Crude Oil & 1.92 & 1.74 & 96.34 & 3.66 \\
\hline Directional to others & 5.15 & 2.03 & 1.36 & \\
\hline \multirow[t]{2}{*}{$\begin{array}{l}\text { Directional including } \\
\text { own }\end{array}$} & 104.37 & 97.94 & 97.7 & $\begin{array}{l}\text { Total spillover } \\
\text { index } 2.85 \%\end{array}$ \\
\hline & $\mathrm{MSCl}$ & $\begin{array}{c}\text { Rapeseed } \\
\text { Oil }\end{array}$ & Crude Oil & $\begin{array}{c}\text { Directional form } \\
\text { others }\end{array}$ \\
\hline $\mathrm{MSCl}$ & 99.40 & 0.034 & 0.56 & 0.59 \\
\hline Rapeseed Oil & 0.89 & 99.08 & 0.03 & 0.92 \\
\hline Crude Oil & 2.04 & 0.83 & 97.13 & 2.87 \\
\hline Directional to others & 2.93 & 0.86 & 0.59 & \\
\hline \multirow[t]{2}{*}{ Directional including own } & 102.33 & 99.94 & 97.72 & $\begin{array}{c}\text { Total spillover } \\
\text { index } 1.46 \%\end{array}$ \\
\hline & $\mathrm{MSCl}$ & Banana & Crude Oil & $\begin{array}{c}\text { Directional form } \\
\text { others }\end{array}$ \\
\hline MSCl & 99.37 & 0.08 & 0.56 & 0.64 \\
\hline Banana & 0.80 & 99.19 & 0.01 & 0.81 \\
\hline Crude Oil & 2.03 & 0.57 & 97.40 & 2.6 \\
\hline Directional to others & 2.83 & 0.65 & 0.57 & \\
\hline Directional including own & 102.2 & 99.84 & 97.97 & $\begin{array}{c}\text { Total spillover } \\
\text { index } 1.35 \%\end{array}$ \\
\hline
\end{tabular}




\begin{tabular}{|c|c|c|c|c|}
\hline & $\mathrm{MSCl}$ & $\begin{array}{l}\text { Cocoa } \\
\text { Beans }\end{array}$ & Crude Oil & $\begin{array}{c}\text { Directional form } \\
\text { others }\end{array}$ \\
\hline MSCI & 99.22 & 0.28 & 0.50 & 0.78 \\
\hline Cocoa Beans & 0.23 & 99.72 & 0.05 & 0.28 \\
\hline Crude Oil & 2.07 & 1.45 & 96.48 & 3.52 \\
\hline Directional to others & 2.30 & 1.73 & 0.55 & \\
\hline \multirow[t]{2}{*}{ Directional including own } & 101.52 & 101.45 & 97.03 & $\begin{array}{c}\text { Total spillover } \\
\text { index } 1.53 \%\end{array}$ \\
\hline & $\mathrm{MSCl}$ & $\begin{array}{c}\text { Ground } \\
\text { nuts }\end{array}$ & Crude Oil & $\begin{array}{c}\text { Directional form } \\
\text { others }\end{array}$ \\
\hline $\mathrm{MSCl}$ & 98.84 & 0.76 & 0.4 & 1.16 \\
\hline Ground nuts & 1.00 & 98.94 & 0.06 & 1.06 \\
\hline Crude Oil & 2.17 & 2.70 & 95.13 & 4.87 \\
\hline Directional to others & 3.17 & 3.46 & 0.46 & \\
\hline \multirow[t]{2}{*}{ Directional including own } & 102.01 & 102.4 & 95.59 & $\begin{array}{c}\text { Total spillover } \\
\text { index } 2.36 \%\end{array}$ \\
\hline & $\mathrm{MSCl}$ & Lamb & Crude Oil & $\begin{array}{c}\text { Directional form } \\
\text { others }\end{array}$ \\
\hline $\mathrm{MSCl}$ & 99.39 & 0.02 & 0.59 & 0.61 \\
\hline Lamb & 1.09 & 97.47 & 1.44 & 2.53 \\
\hline Crude Oil & 2.02 & 0.68 & 97.30 & 2.70 \\
\hline Directional to others & 3.11 & 0.70 & 2.03 & \\
\hline \multirow[t]{2}{*}{ Directional including own } & 102.5 & 98.17 & 99.33 & $\begin{array}{c}\text { Total spillover } \\
\text { index } 1.95 \%\end{array}$ \\
\hline & $\mathrm{MSCl}$ & Beef & Crude Oil & $\begin{array}{c}\text { Directional form } \\
\text { others }\end{array}$ \\
\hline $\mathrm{MSCl}$ & 99.40 & 0.05 & 0.55 & 0.60 \\
\hline Beef & 1.96 & 97.66 & 0.38 & 2.34 \\
\hline Crude Oil & 2.01 & 1.40 & 96.59 & 3.41 \\
\hline Directional to others & 3.97 & 1.45 & 0.93 & \\
\hline \multirow[t]{2}{*}{ Directional including own } & 103.37 & 99.11 & 97.52 & $\begin{array}{c}\text { Total spillover } \\
\text { index } 2.12 \% \\
\end{array}$ \\
\hline & $\mathrm{MSCl}$ & Fish & Crude Oil & $\begin{array}{c}\text { Directional form } \\
\text { others }\end{array}$ \\
\hline $\mathrm{MSCl}$ & 99.21 & 0.24 & 0.54 & 0.78 \\
\hline Fish & 3.23 & 96.60 & 0.17 & 3.4 \\
\hline Crude Oil & 1.97 & 0.28 & 97.74 & 2.25 \\
\hline Directional to others & 5.20 & 0.52 & 0.71 & \\
\hline Directional including own & 104.41 & 97.12 & 98.45 & $\begin{array}{c}\text { Total spillover } \\
\text { index } 2.14 \%\end{array}$ \\
\hline
\end{tabular}


Table 4: Optimal portfolios weights and hedge ratios

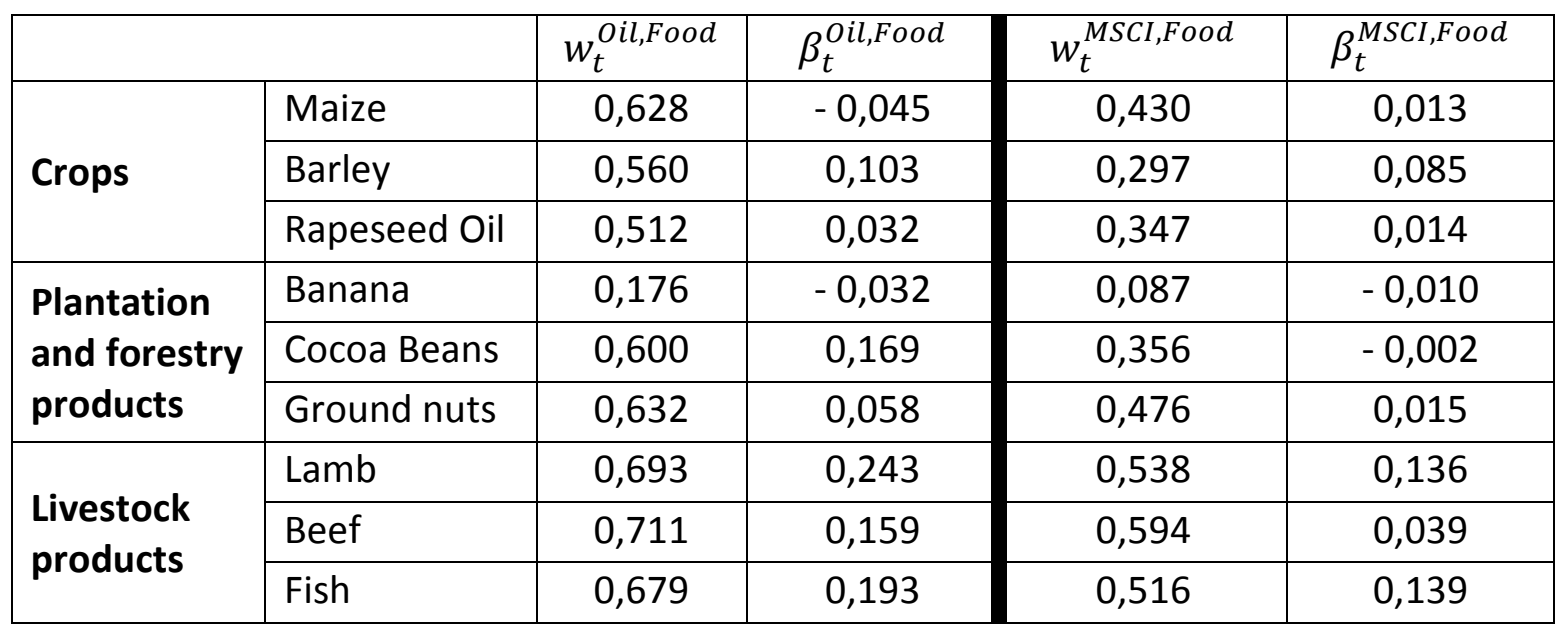


Table 5: Hedge effectiveness

\begin{tabular}{|l|c|c|c|c|}
\hline \multirow{2}{*}{} & \multicolumn{2}{|c|}{ Oil-Food Portfolio } & \multicolumn{2}{c|}{ MSCI-Food Portfolio } \\
\cline { 2 - 5 } & Variance (\%) & HE (\%) & Variance (\%) & HE (\%) \\
\hline Maize & 0,345 & 0,560 & 0,345 & $-0,747$ \\
\hline Barley & 0,532 & 0,322 & 0,532 & $-1,694$ \\
\hline Rapeseed Oil & 0,740 & 0,057 & 0,740 & $-2,748$ \\
\hline Banana & 3,28 & $-3,181$ & 3,28 & $-15,611$ \\
\hline Cocoa Beans & 0,372 & 0,526 & 0,372 & $-0,884$ \\
\hline Ground nuts & 0,652 & 0,169 & 0,652 & $-2,302$ \\
\hline Lamb & 0,184 & 0,765 & 0,184 & 0,068 \\
\hline Beef & 0,143 & 0,818 & 0,143 & 0,276 \\
\hline Fish & 0,228 & 0,709 & 0,228 & $-0,155$ \\
\hline
\end{tabular}




\section{Appendix 1}

\section{Commodities list:}

- Bananas, Central American and Ecuador, FOB U.S. Ports, US\$ per metric ton,

- Barley, Canadian no.1 Western Barley, spot price, US\$ per metric ton,

- Beef, Australian and New Zealand 85\% lean fores, CIF U.S. import price, US cents per pound,

- Cocoa beans, International Cocoa Organization cash price, CIF US and European ports, US\$ per metric ton,

- Rapeseed oil, crude, fob Rotterdam, US\$ per metric ton,

- Fishmeal, Peru Fish meal/pellets $65 \%$ protein, $\mathrm{CIF}$, US\$ per metric ton,

- Groundnuts (peanuts), 40/50 (40 to 50 count per ounce), cif Argentina, US\$ per metric ton,

- Lamb, frozen carcass Smithfield London, US cents per pound,

- Maize (corn), U.S. No.2 Yellow, FOB Gulf of Mexico, U.S. price, US\$ per metric ton,

- Crude Oil (petroleum), Price index, $2005=100$, simple average of three spot prices, 


\section{Appendix 2}

Histogram of rendementRapeseedOil

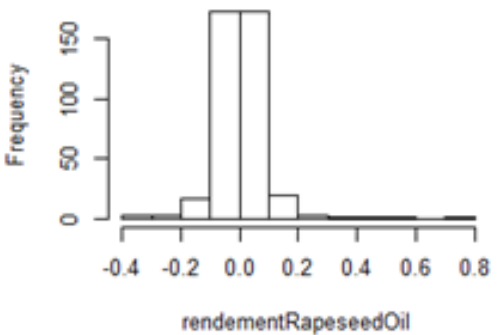

Histogram of rendementBeef

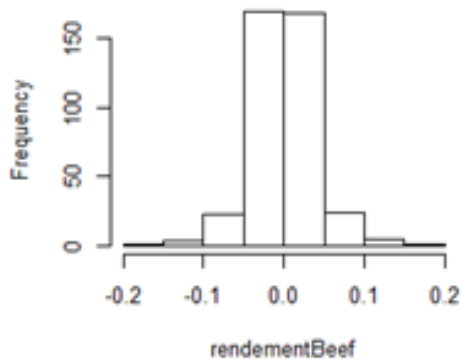

Histogram of rendementBanana

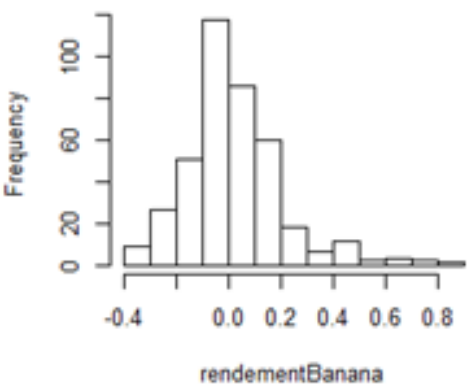

Histogram of rendementGroudNuts

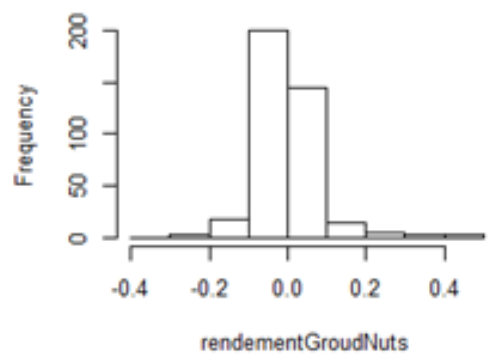

Histogram of rendementFish

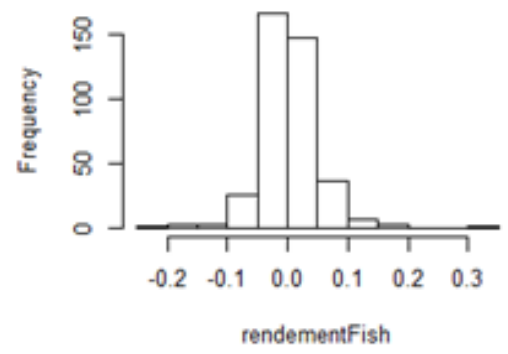

Histogram of rendementBarley

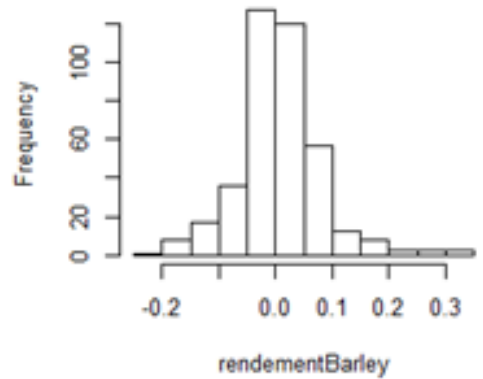

Histogram of rendementBeans

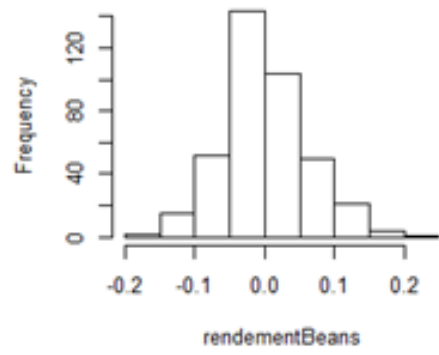

Histogram of rendementLamb

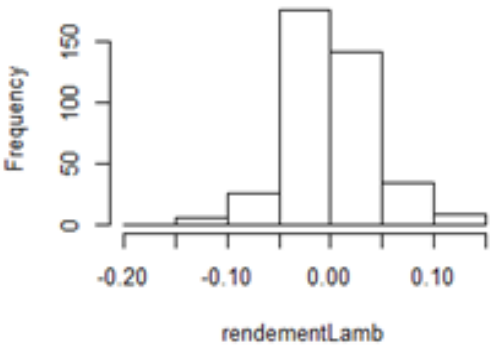

Histogram of rendementMaiz

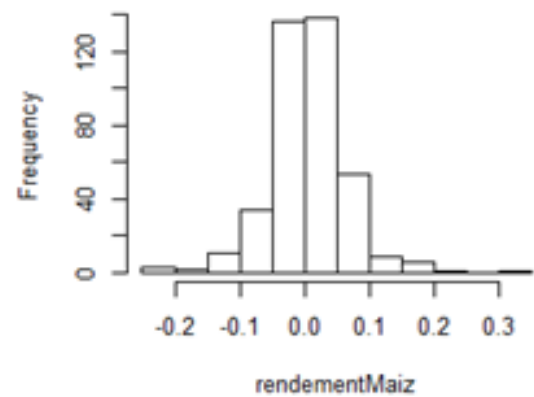

Histogram of rendementOILBRE

Histogram of rendementMSCI
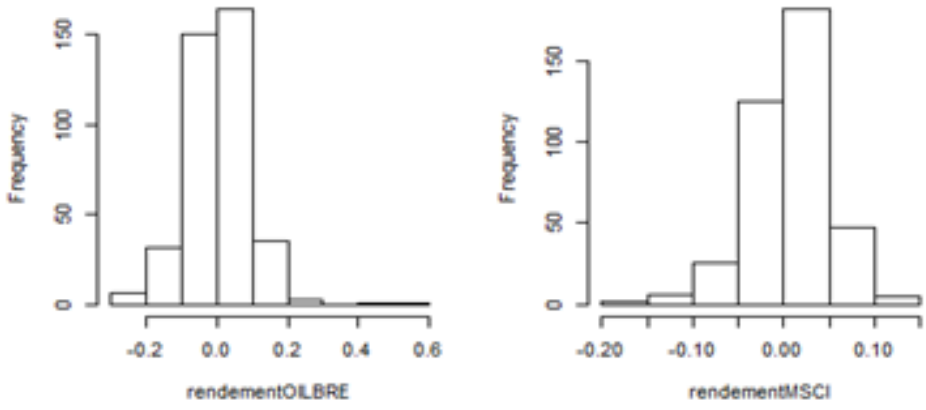

Figure 1: Histogram of return series 

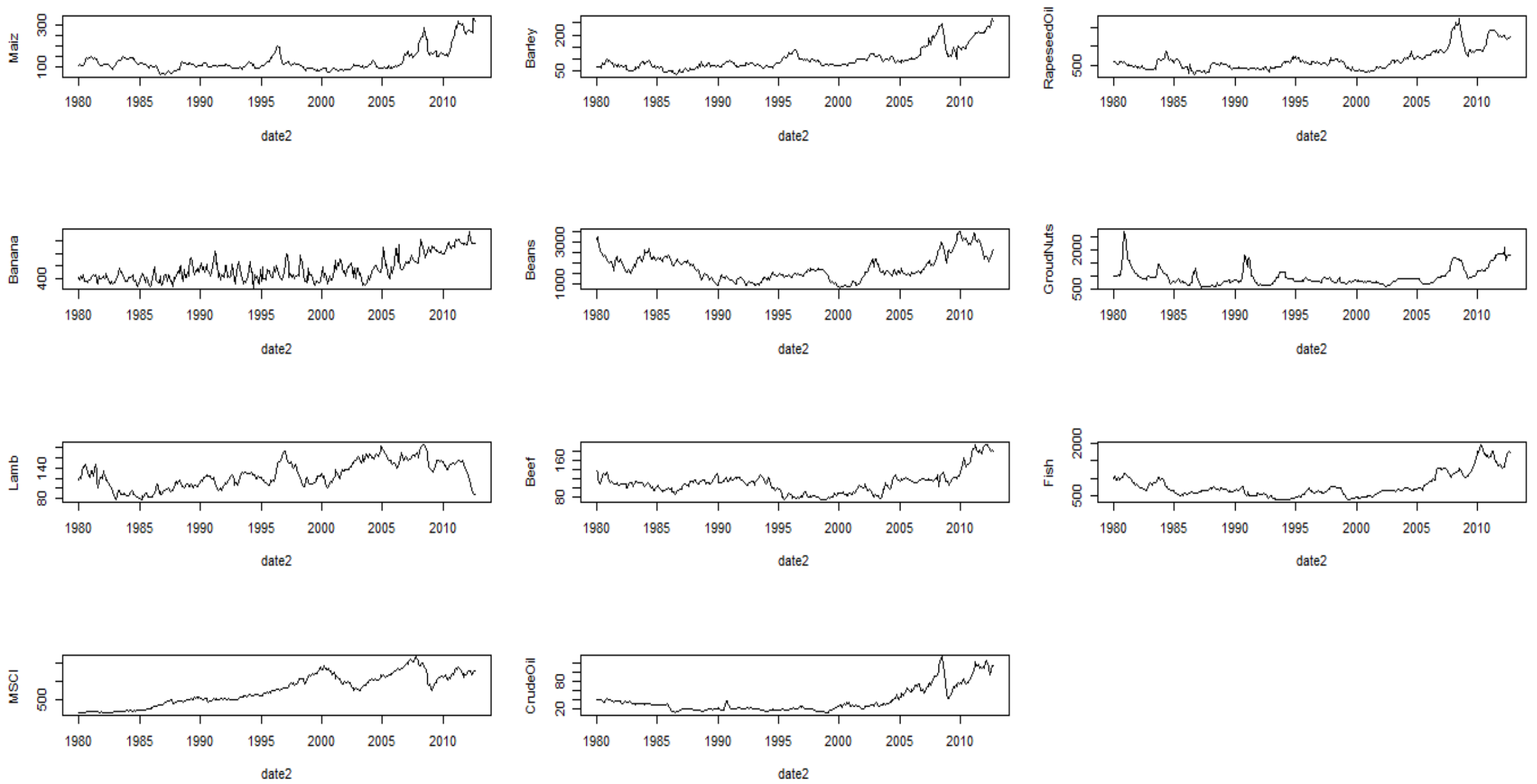

Figure 2: Food commodities, energy commodities and MSCl index prices for the period 1980-2012 (Source: IMF and MSCI Company) 


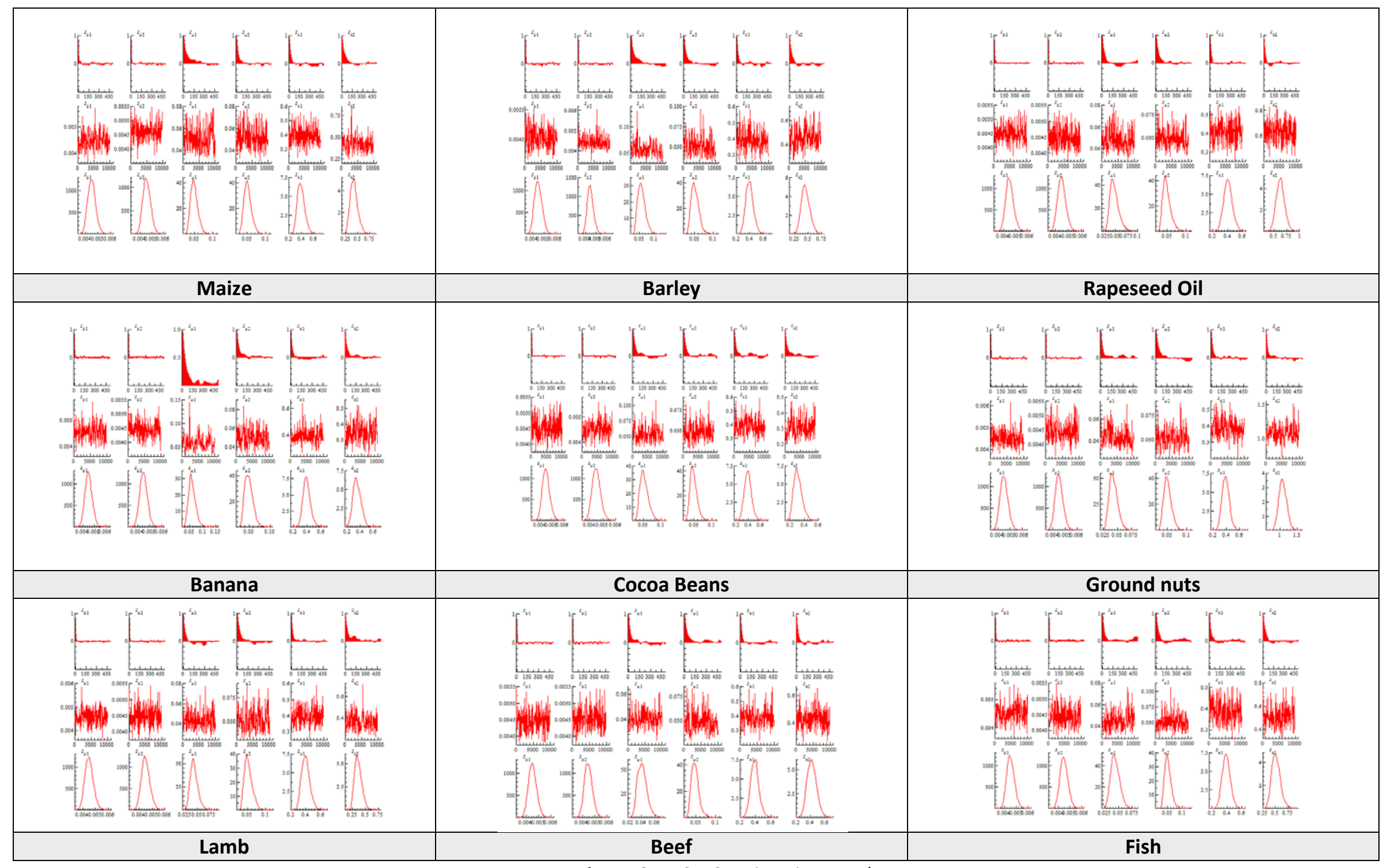

Figure 3: $\mathrm{MCMC}$ estimation results

(sample autocorrelations, sample paths and posterior densities) 


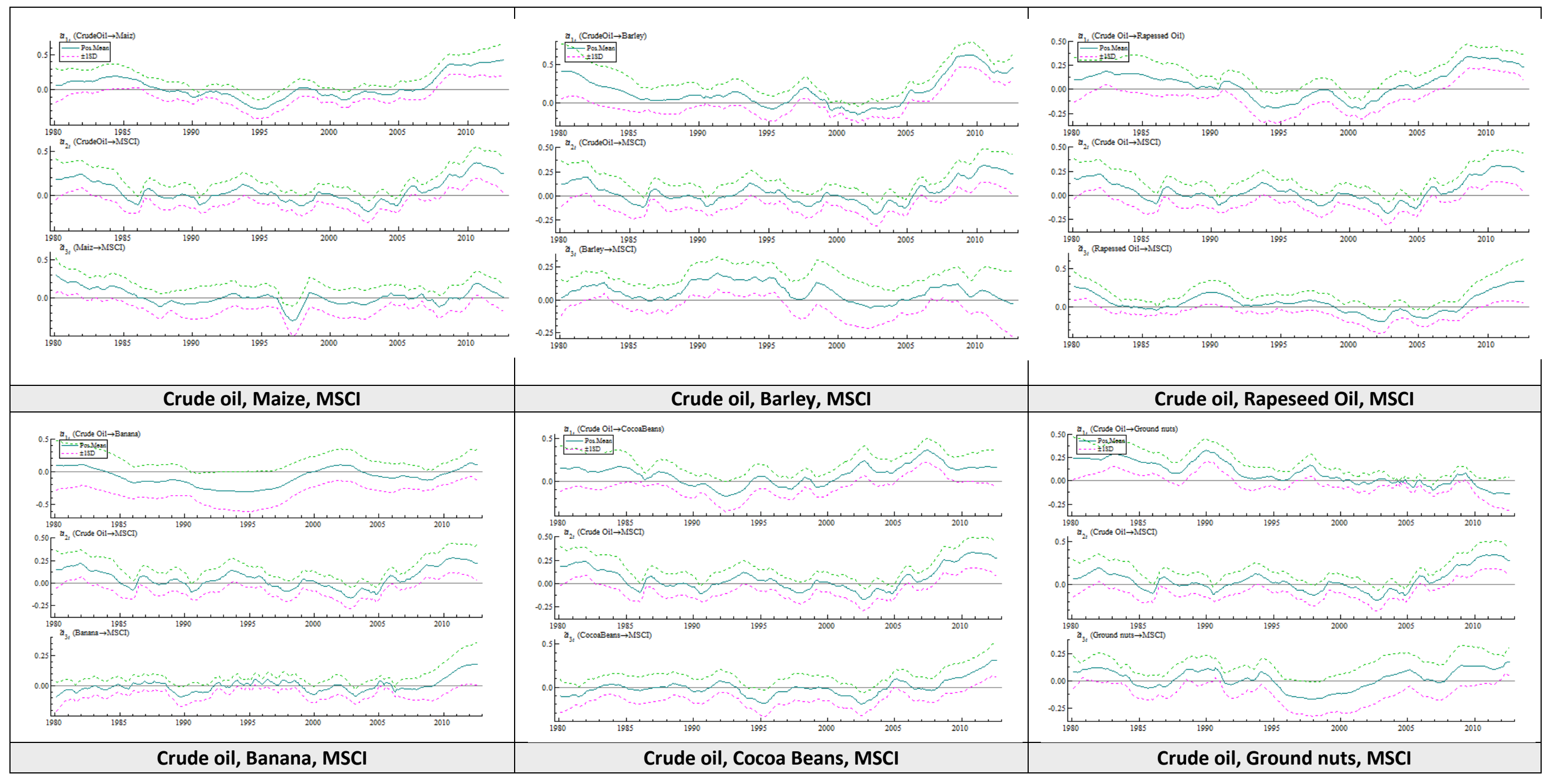




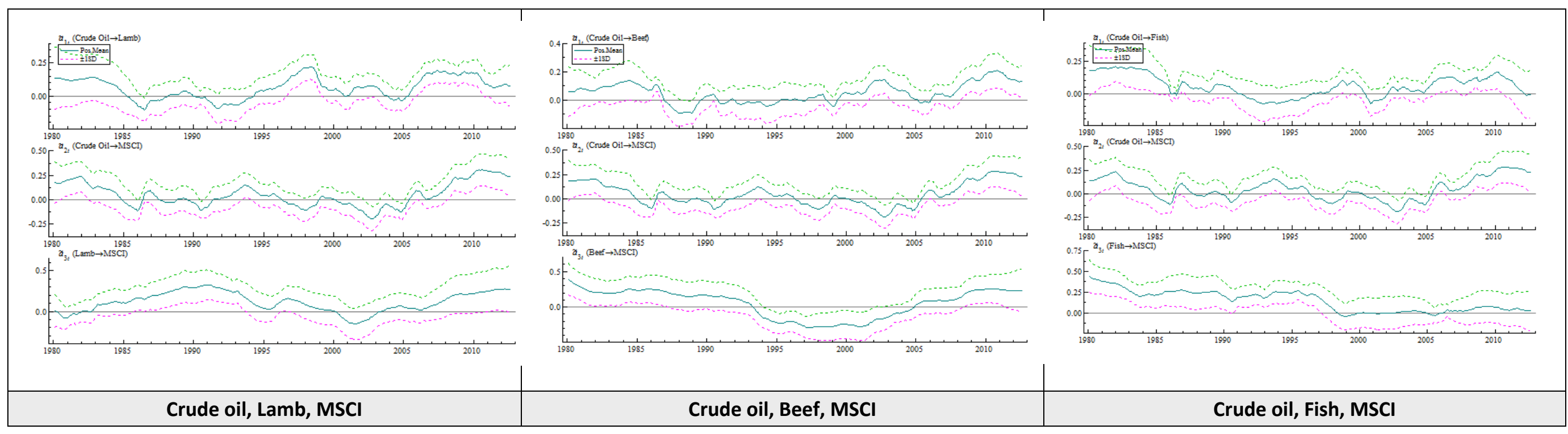

Figure 4: Simultaneous relation posterior estimates 


\section{Appendix 3}

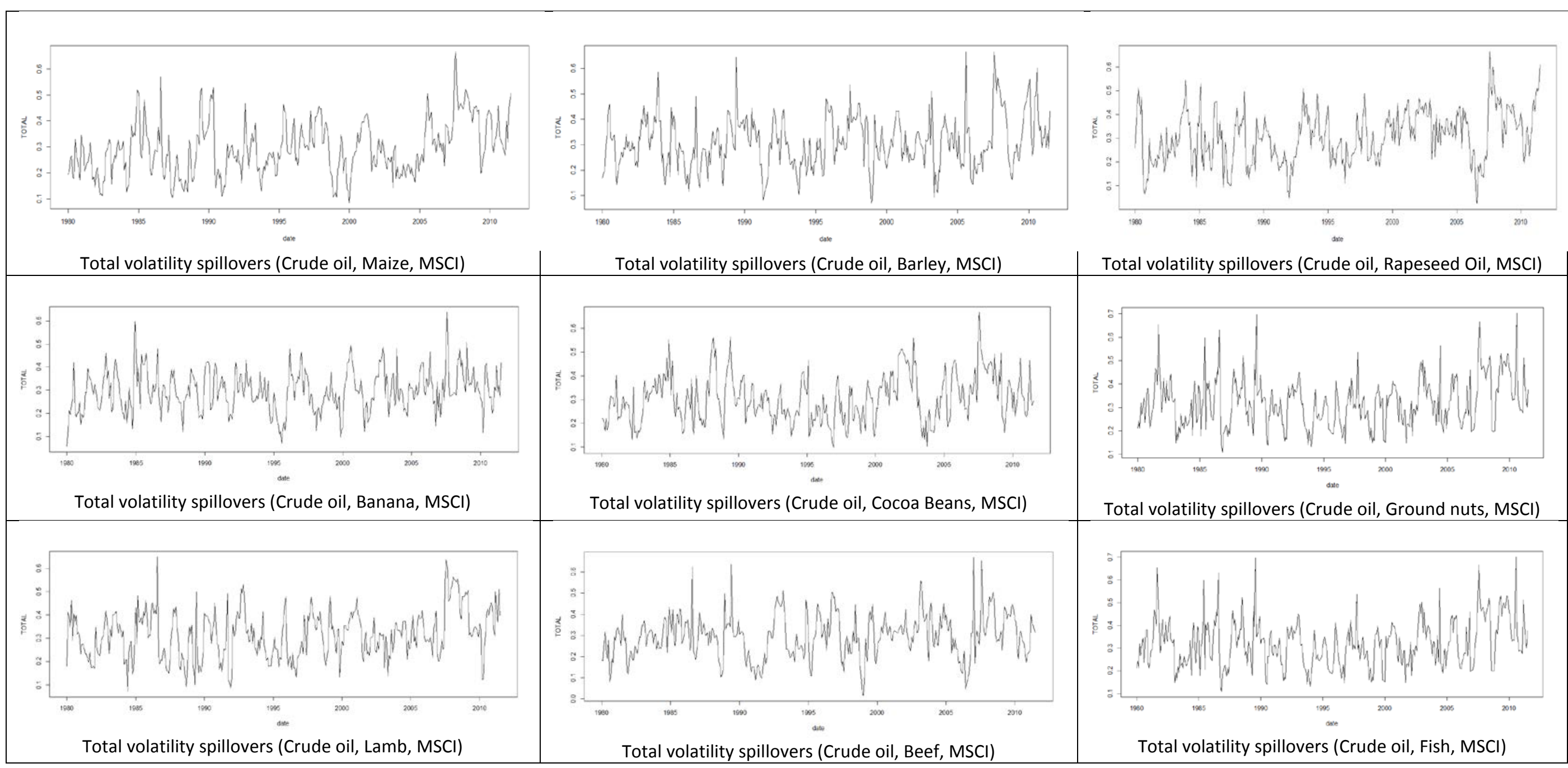

Figure 1: Total volatility spillovers (in each set composed of 3 types of asset classes: Energy, Food and Stocks) 


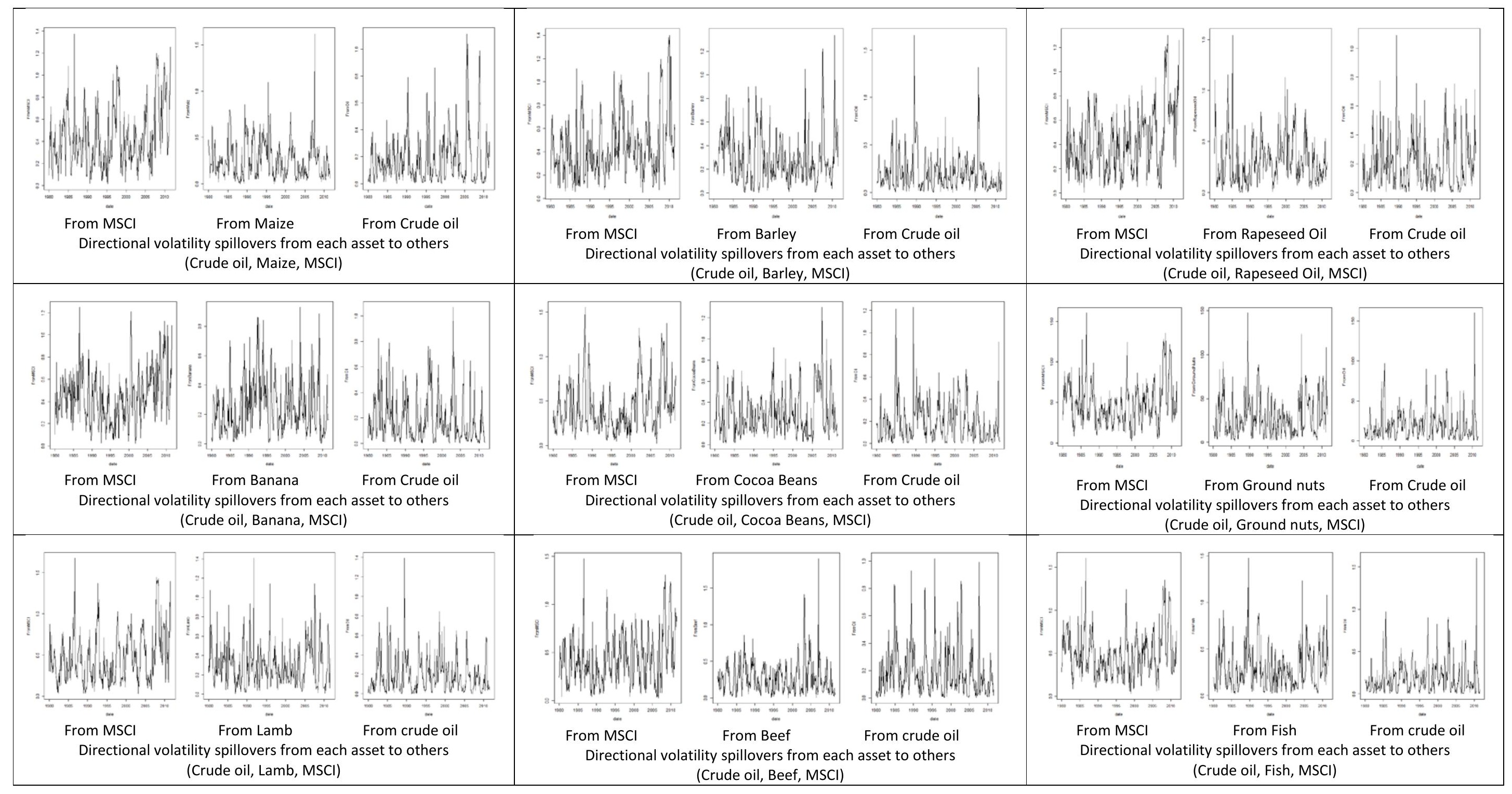

Figure 3 : Directional volatility spillovers from each asset to others 


\section{Appendix 4}

athognal inpuse Response rom menderentoL BRE

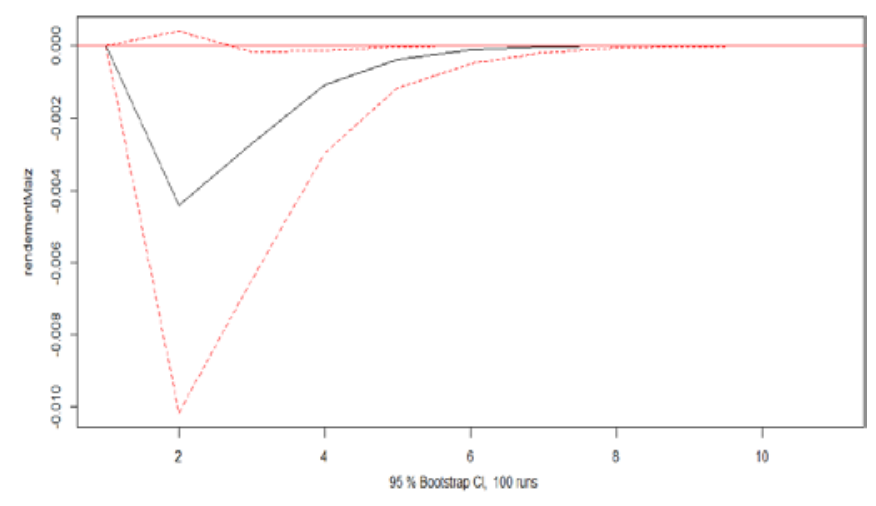

Onsogonal houke Resporse tom rendementMSCI

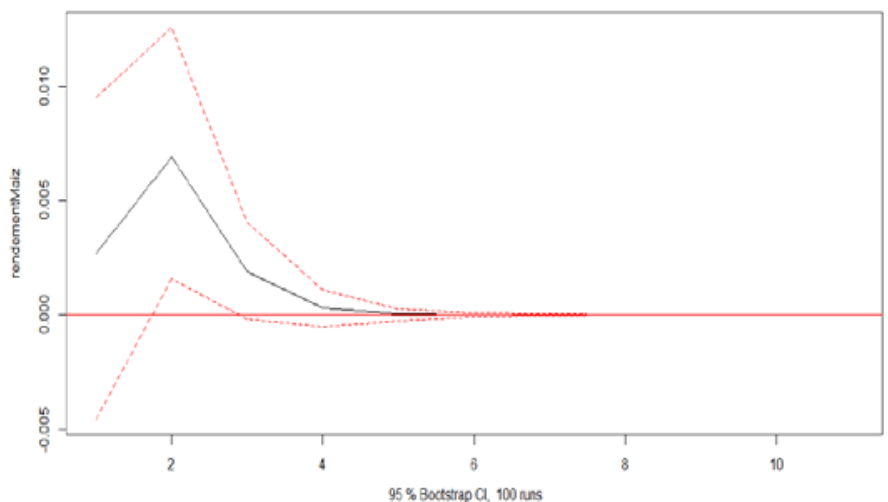

(a) Constant VAR model

SVAR micuse Response from resdementol BRE

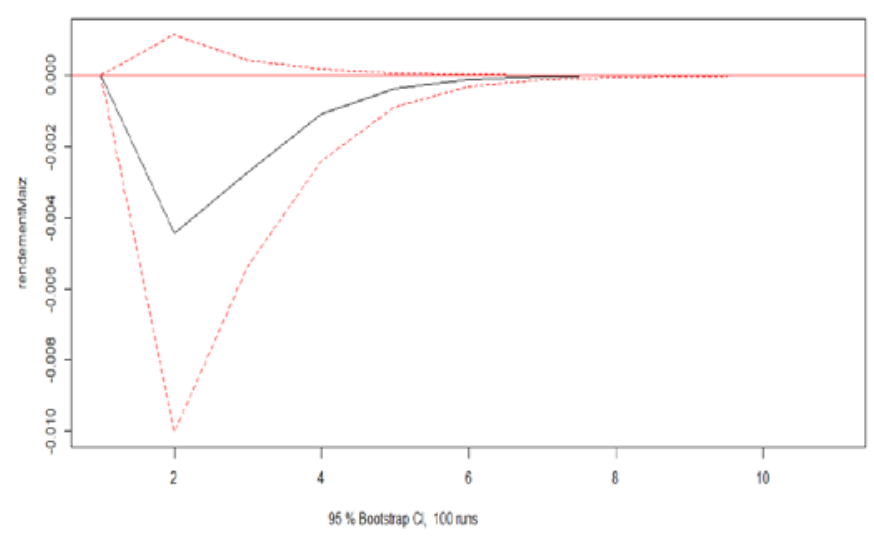

SVAR mouke Resporse tom rendentertuISC

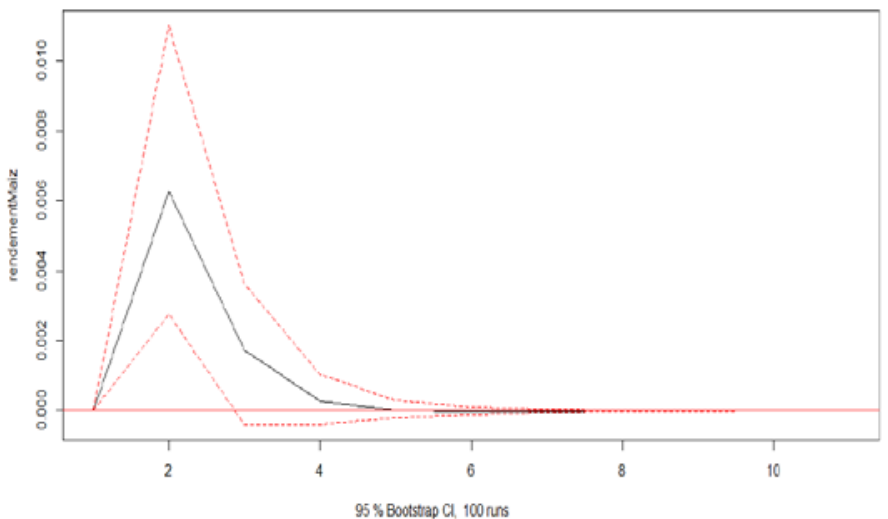

(b) Constant SVAR model
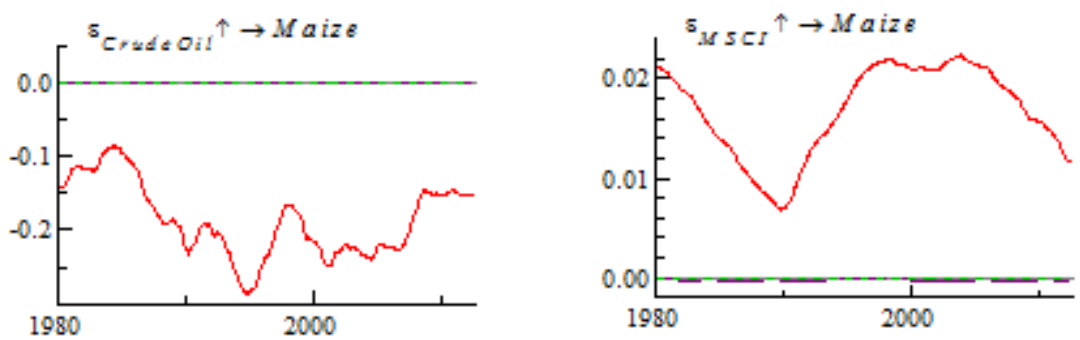

(c) TVP-VAR model

Figure 1: Impulse responses for the set Crude oil, Maize, MSCI 

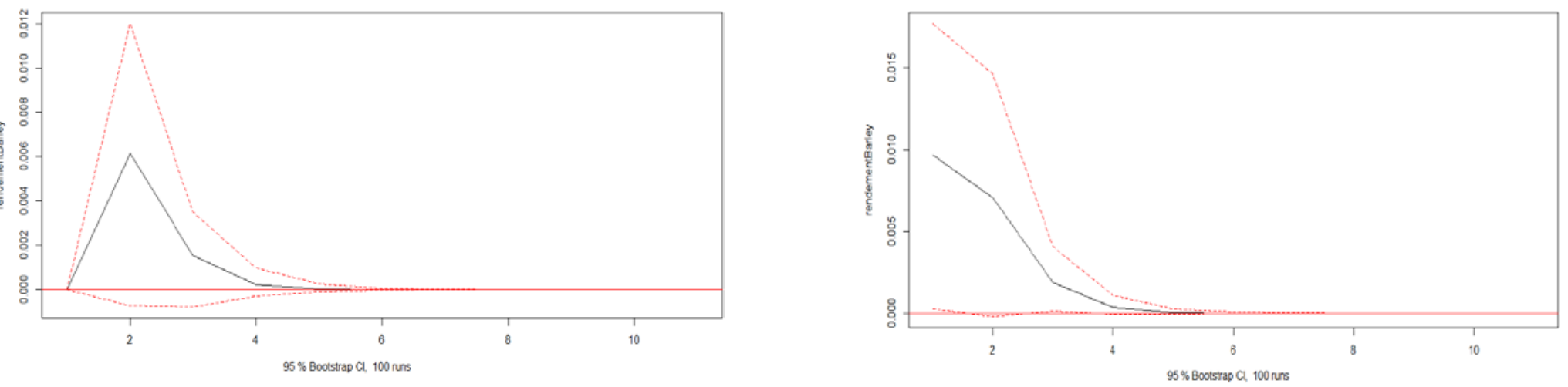

(a) Constant VAR model

SVAR Impulse Responsefrom rendenentoLBRE

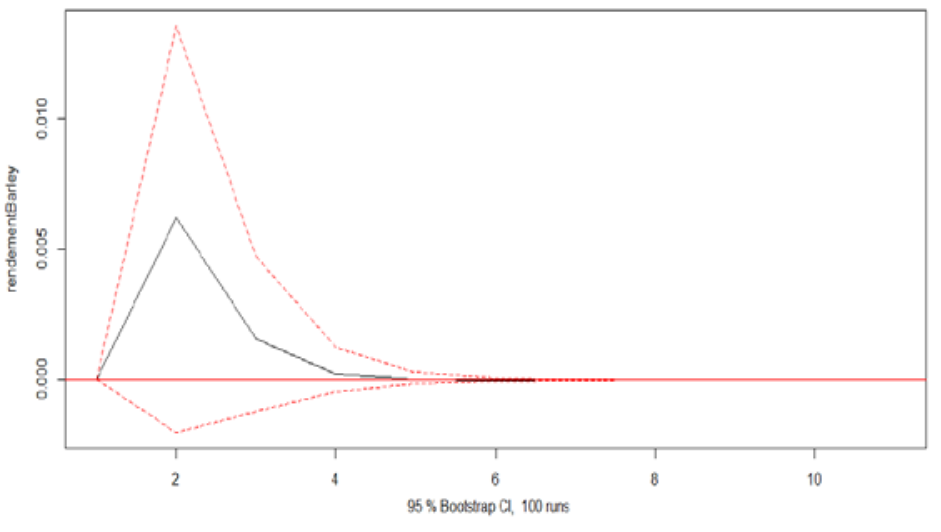

SVAR imcuse Response from rendemertuSCI

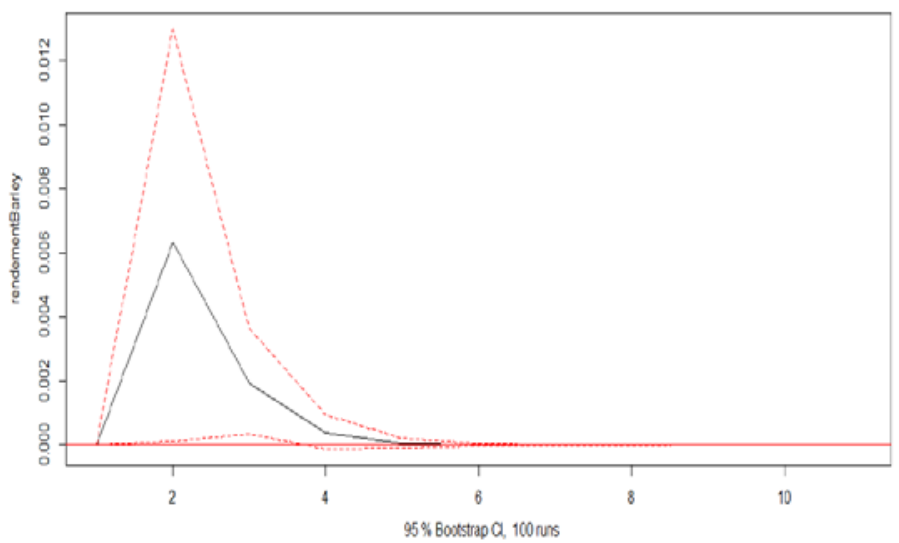

(b) Constant SVAR model
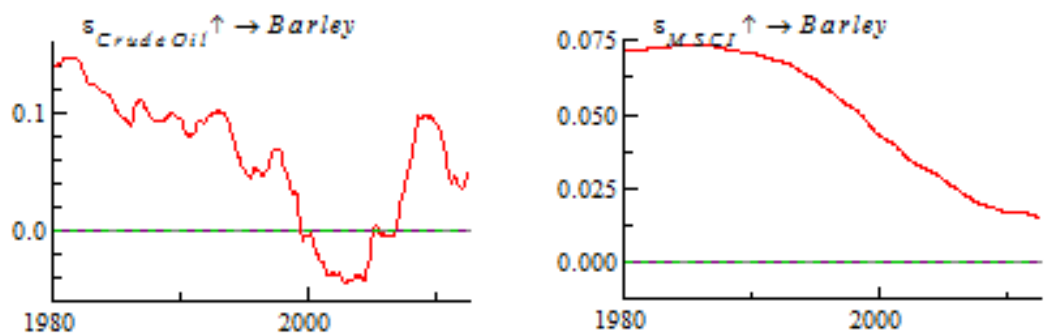

(c) TVP-VAR model

Figure 2: Impulse responses for the set Crude oil, Barley, $\mathrm{MSCl}$ 
Orthogonal Impulse Response from rendementOL LRE

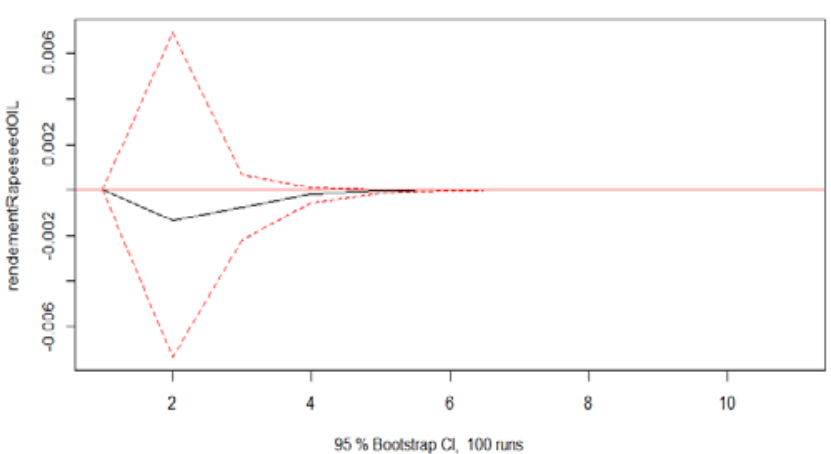

Orthogonal Impulse Response from rendementMSCI

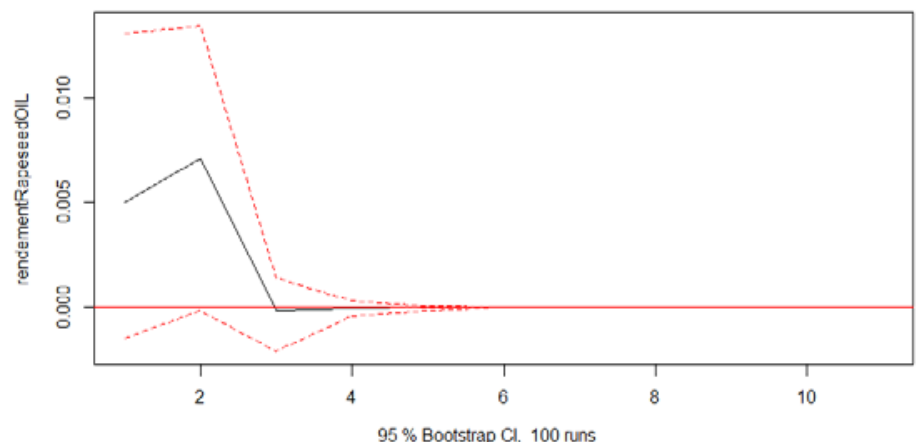

(a) Constant VAR model

SVAR Impulse Response from rendementMSCI
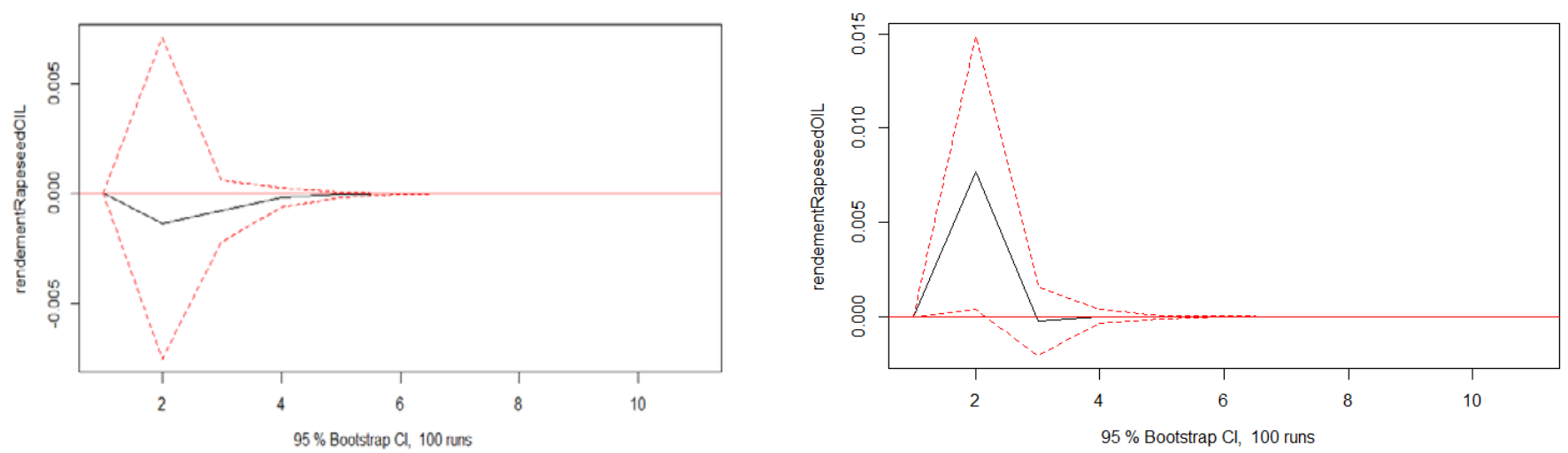

(b) Constant SVAR model
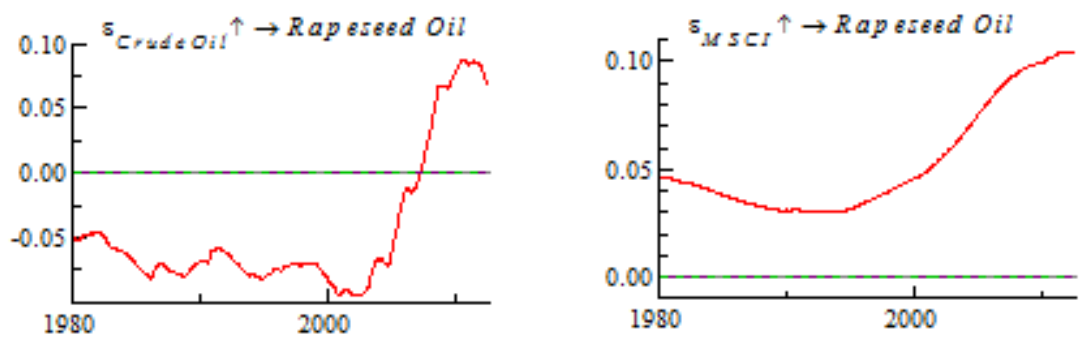

(c) TVP-VAR model

Figure 3: Impulse responses for the set Crude oil, Rapeseed oil, MSCI 

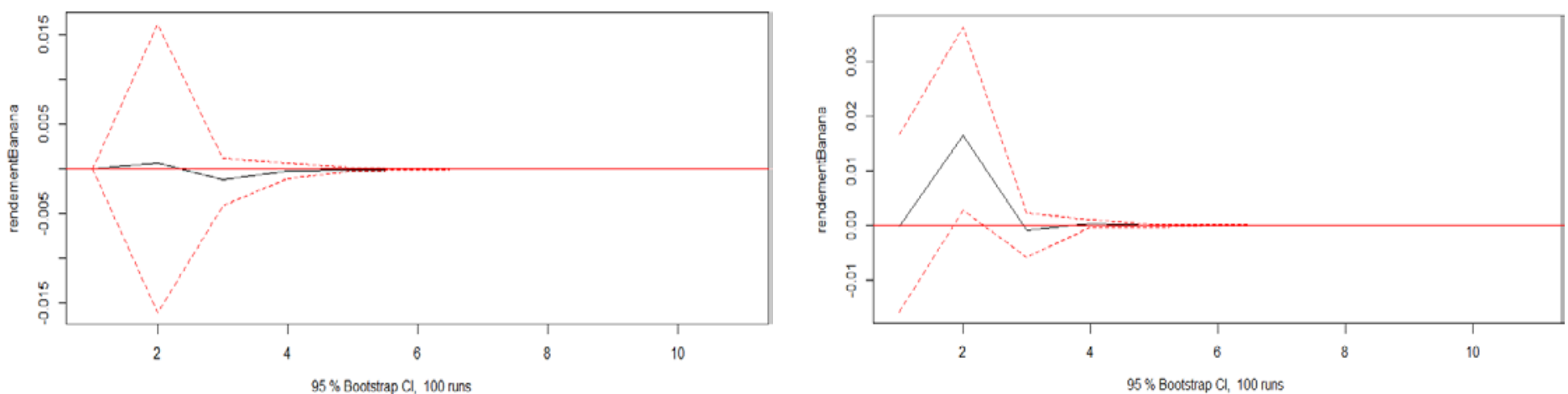

(a) Constant VAR model

SVAR Impulse Response from rendementOILBRE

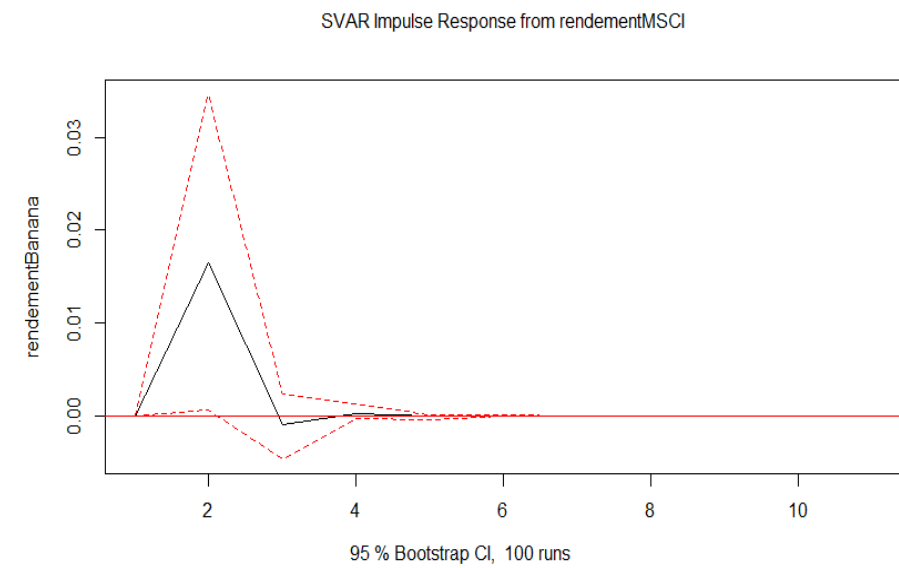

(b) Constant SVAR model
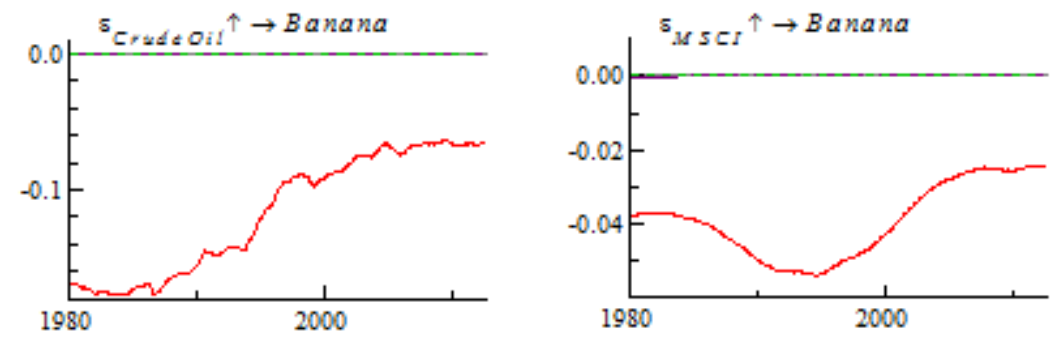

(c) TVP-VAR model

Figure 4: Impulse responses for the set Crude oil, Banana, MSCI 

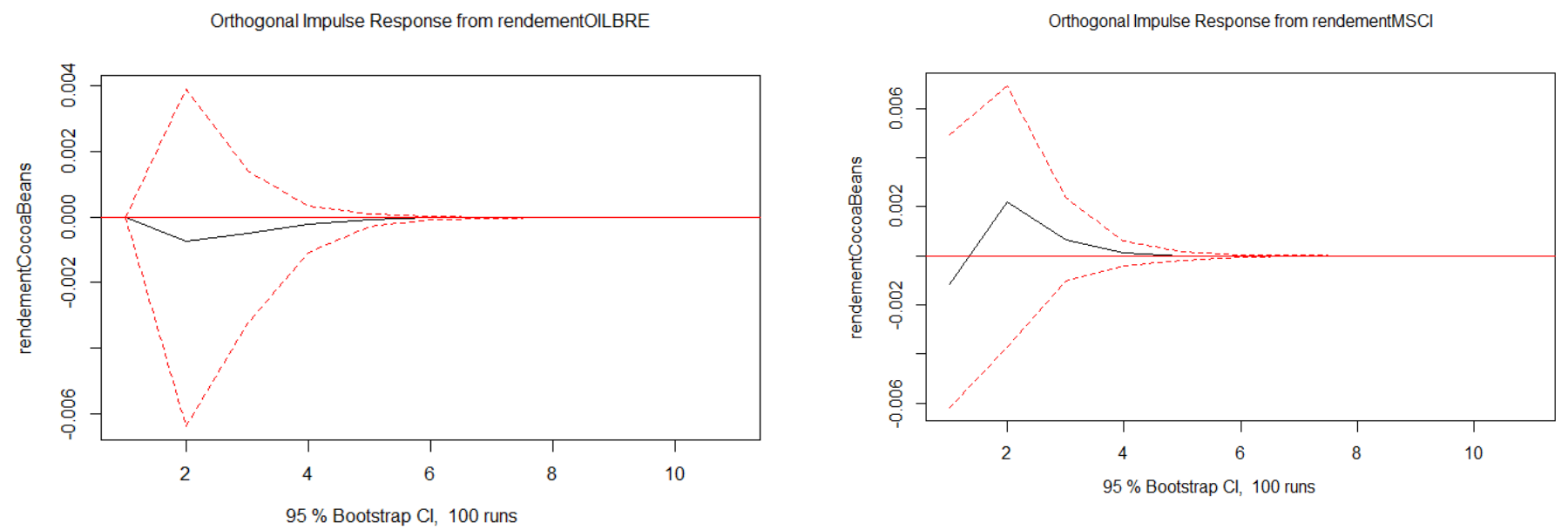

(a) Constant VAR model

SVAR Impulse Response from rendementOILBRE

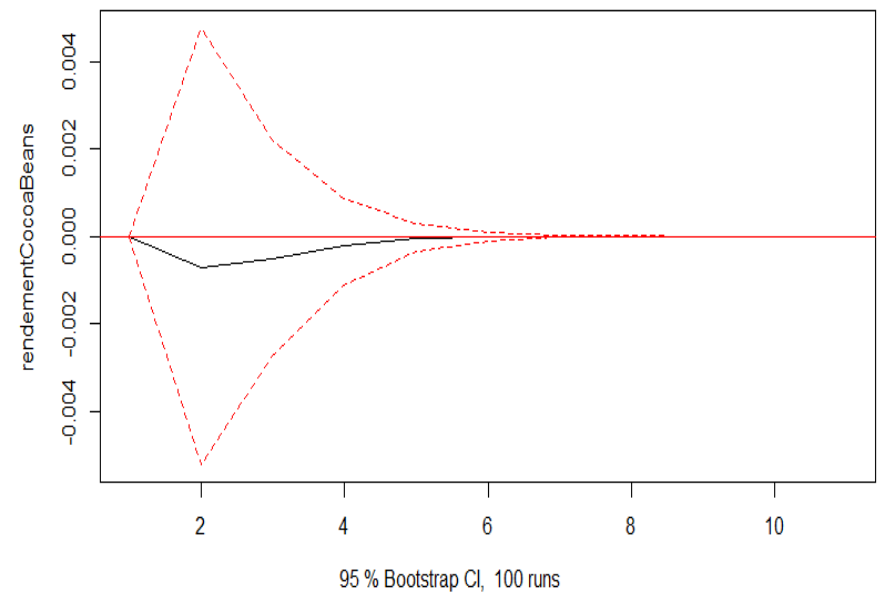

SVAR Impulse Response from rendementMSCI

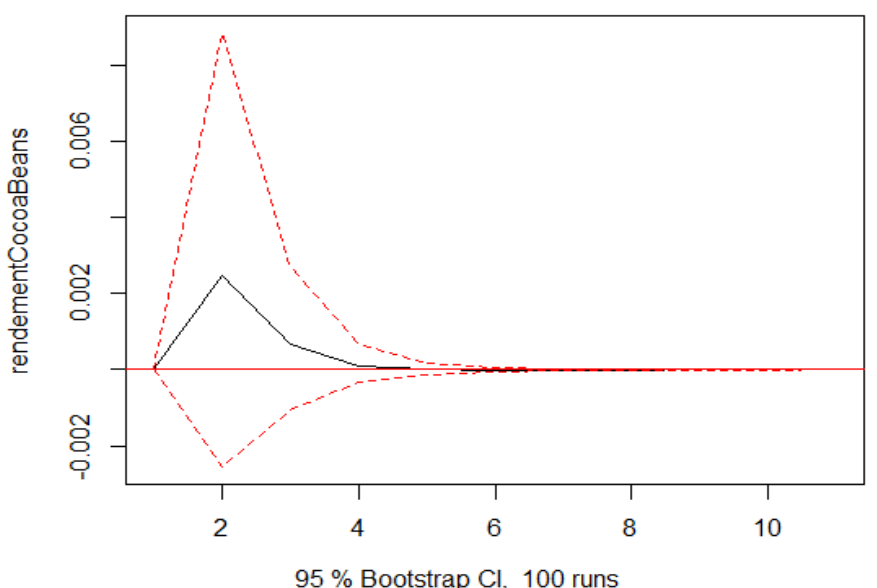

(b) Constant SVAR model
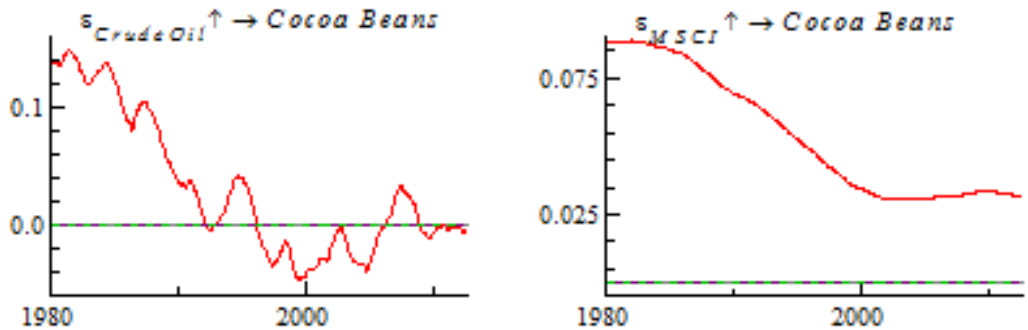

(c) TVP-VAR model

Figure 5: Impulse responses for the set Crude oil, Cocoa beans, MSCI 

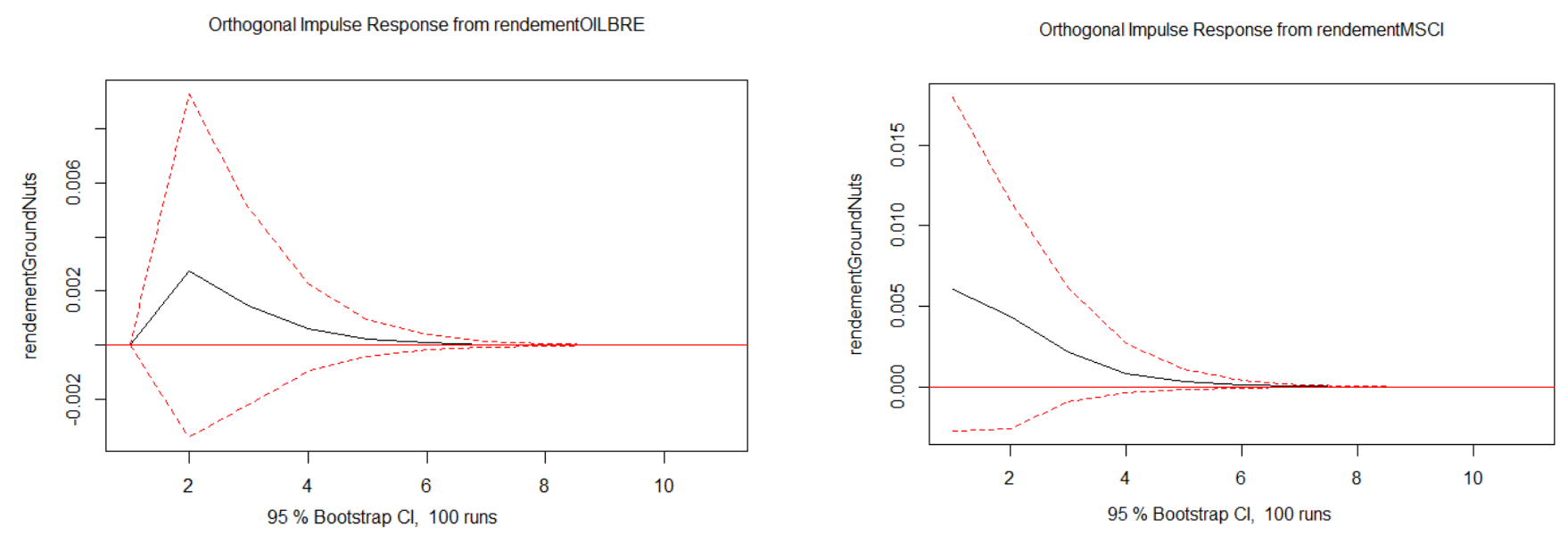

(a) Constant VAR model
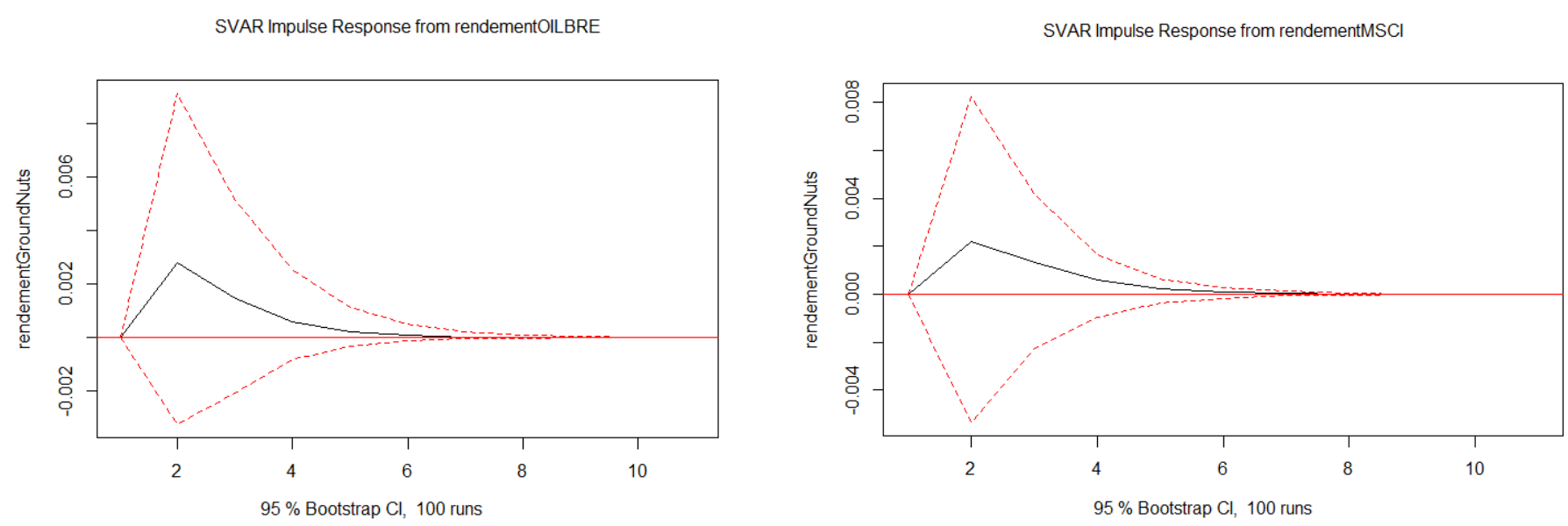

(b) Constant SVAR model
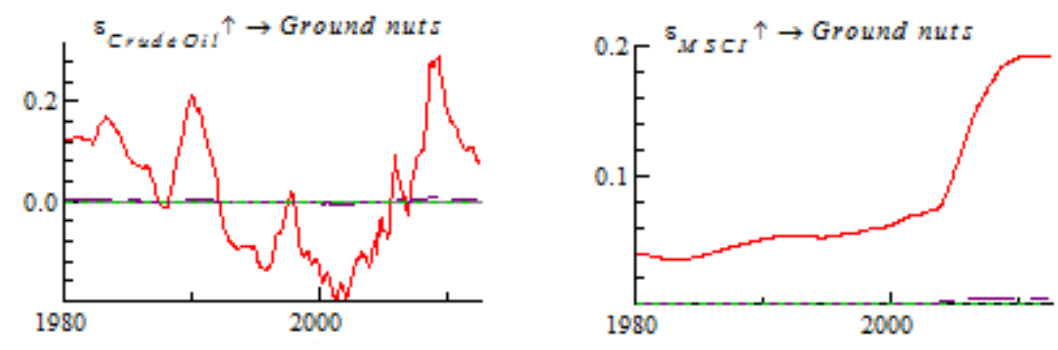

(c) TVP-VAR model

Figure 6: Impulse responses for the set Crude oil, Ground nuts, MSCI 

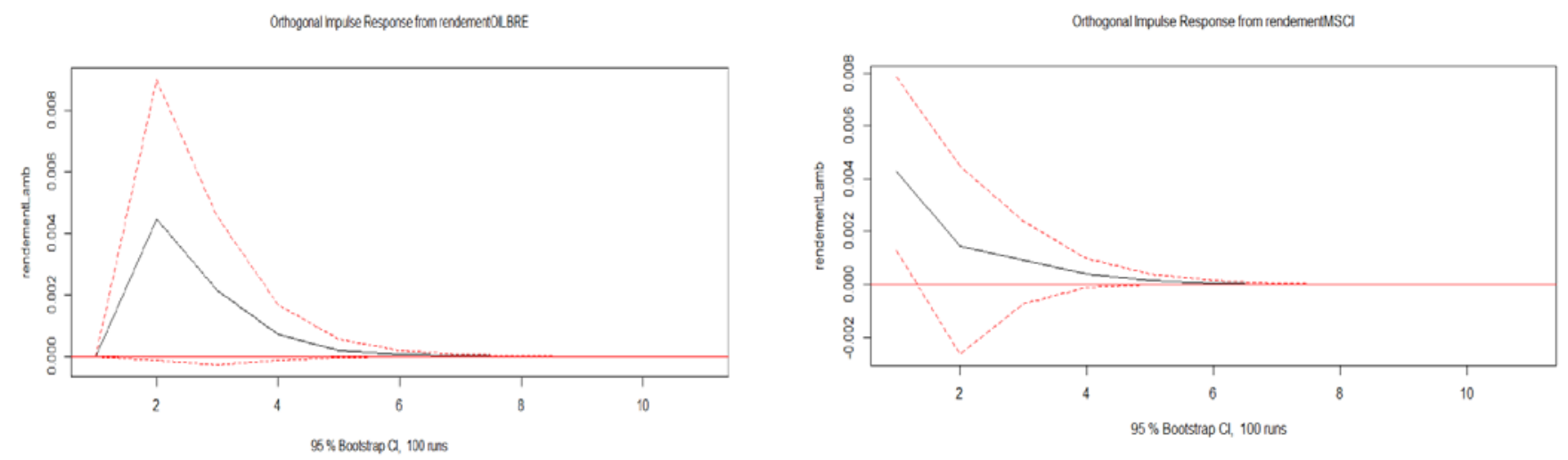

(a) Constant VAR model
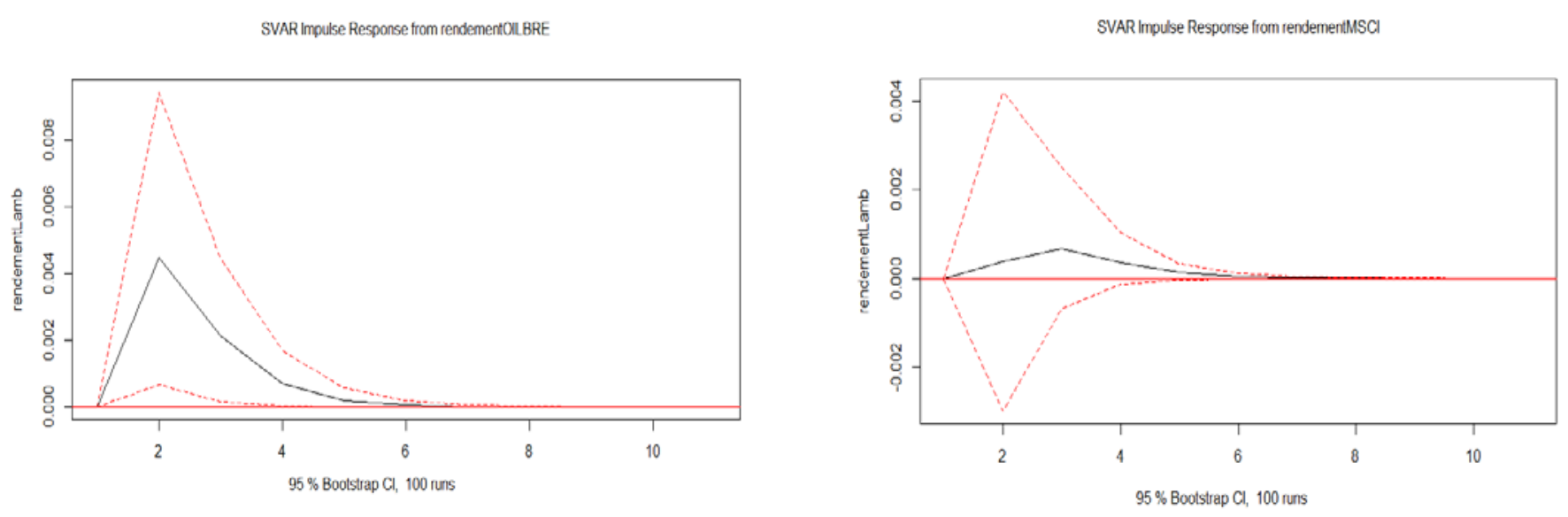

(b) Constant SVAR model
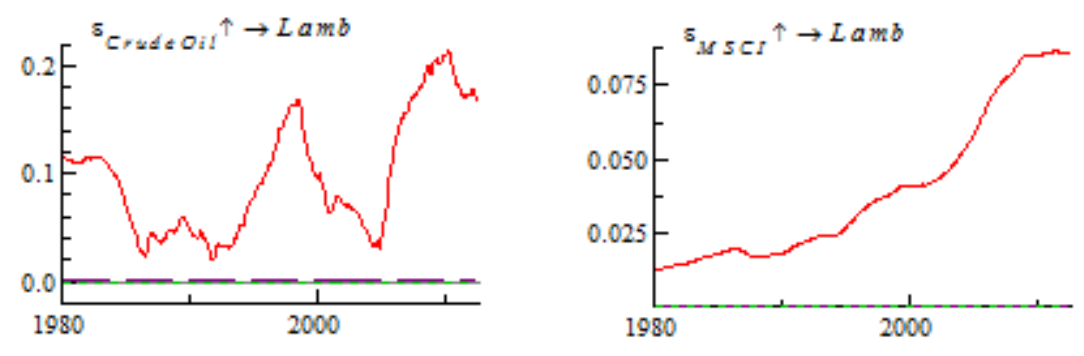

(c) TVP-VAR model

Figure 7: Impulse responses for the set Crude oil, Lamb, MSCI 
Orthogonal Impulse Response from rendementOILBRE

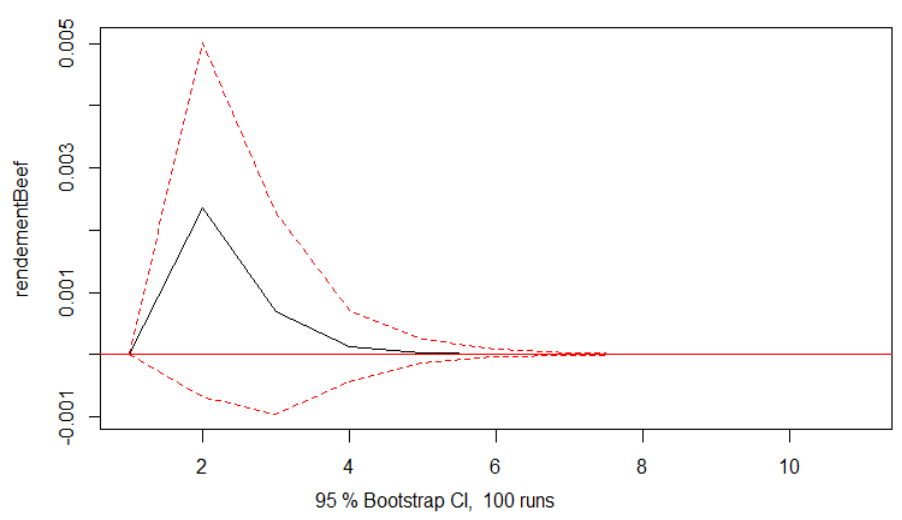

Orthogonal Impulse Response from rendementMSCl

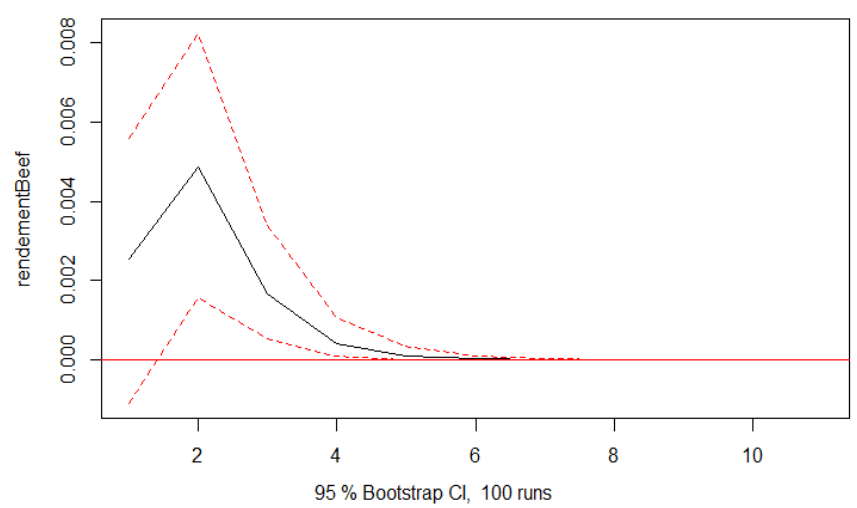

(a) Constant VAR model

SVAR Impulse Response from rendementOILBRE

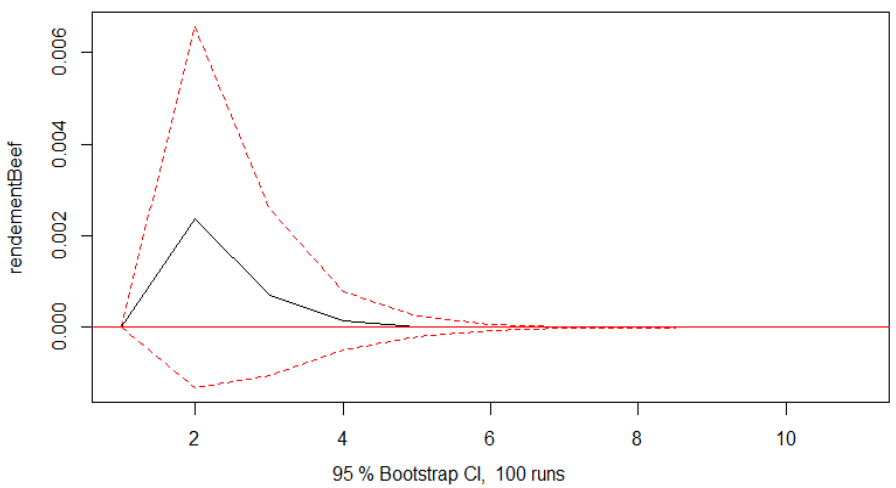

SVAR Impulse Response from rendementMSCl

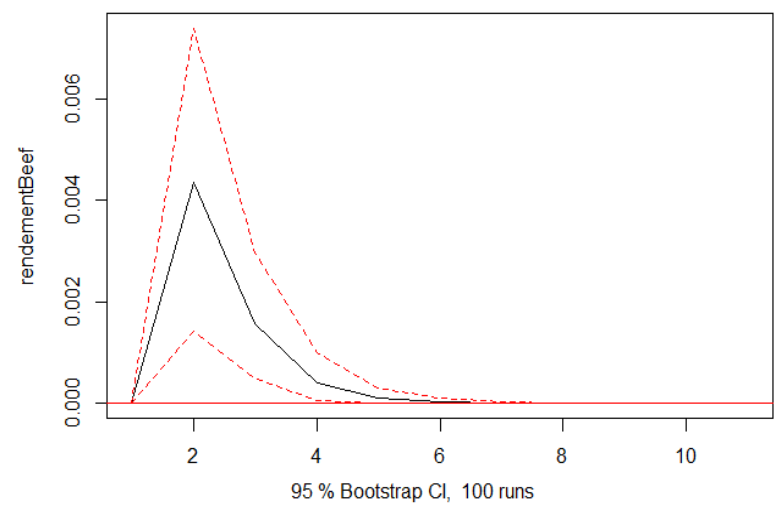

(b) Constant SVAR model
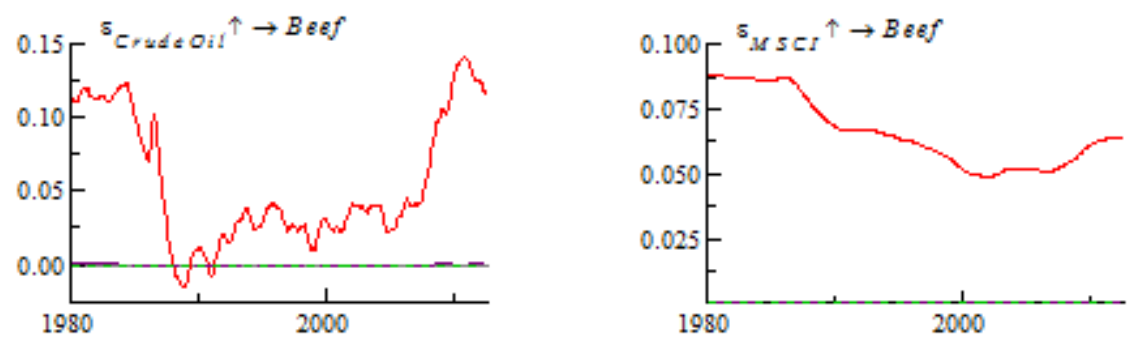

(c) TVP-VAR model

Figure 8: Impulse responses for the set Crude oil, Beef, MSCI 
Orthogonal Impulse Response from rendementOILBRE

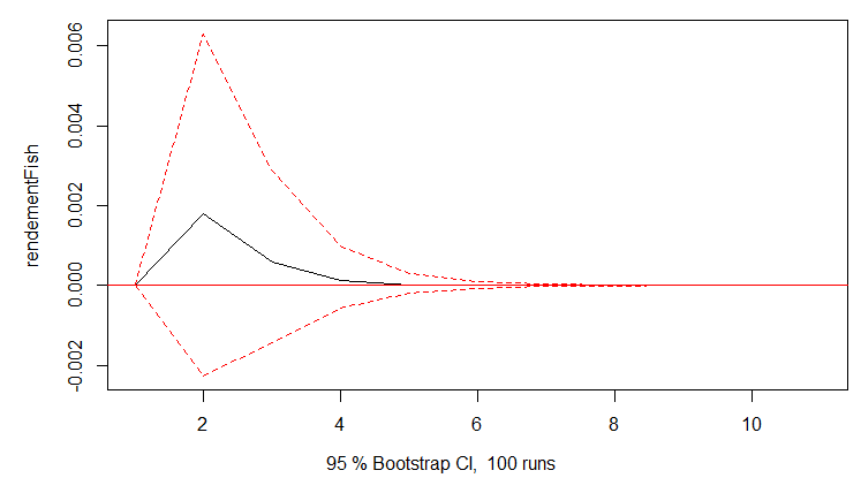

Orthogonal Impulse Response from rendementMSCl

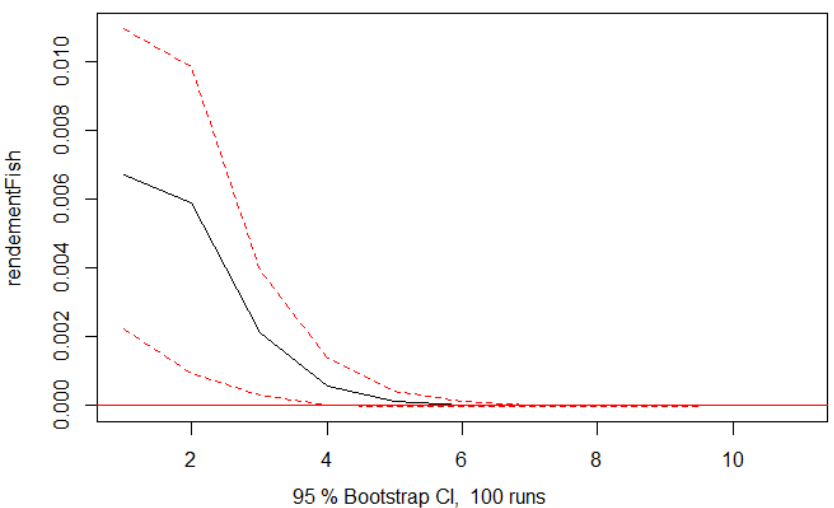

(a) Constant VAR model

SVAR Impulse Response from rendementOILBRE

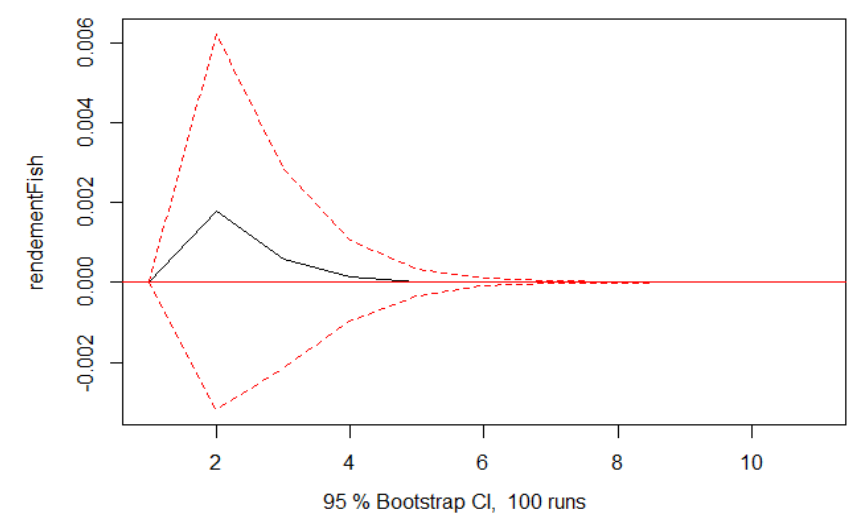

SVAR Impulse Response from rendementMSCI

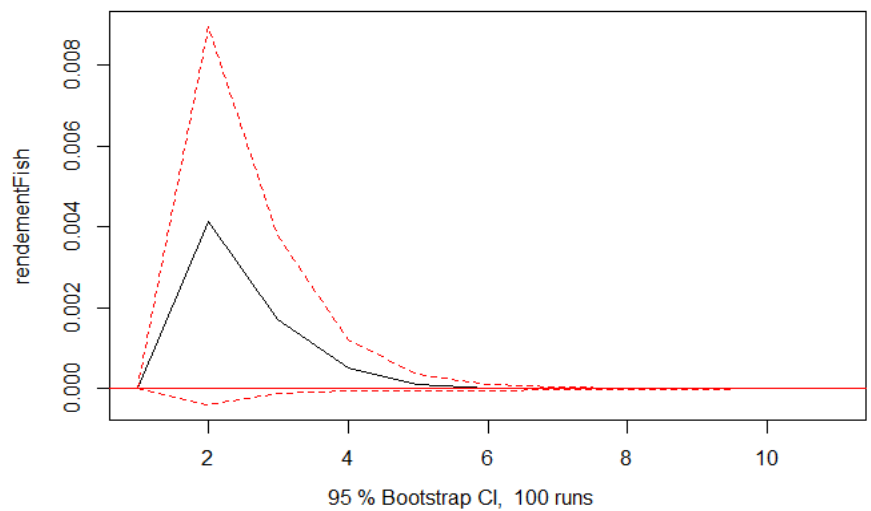

(b) Constant SVAR model
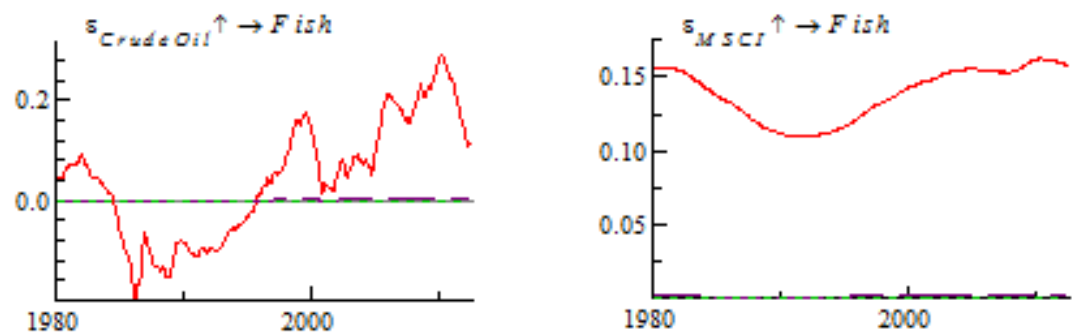

(c) TVP-VAR model

Figure 9: Impulse responses for the set Crude oil, Fish, MSCI 


\section{Appendix 5}
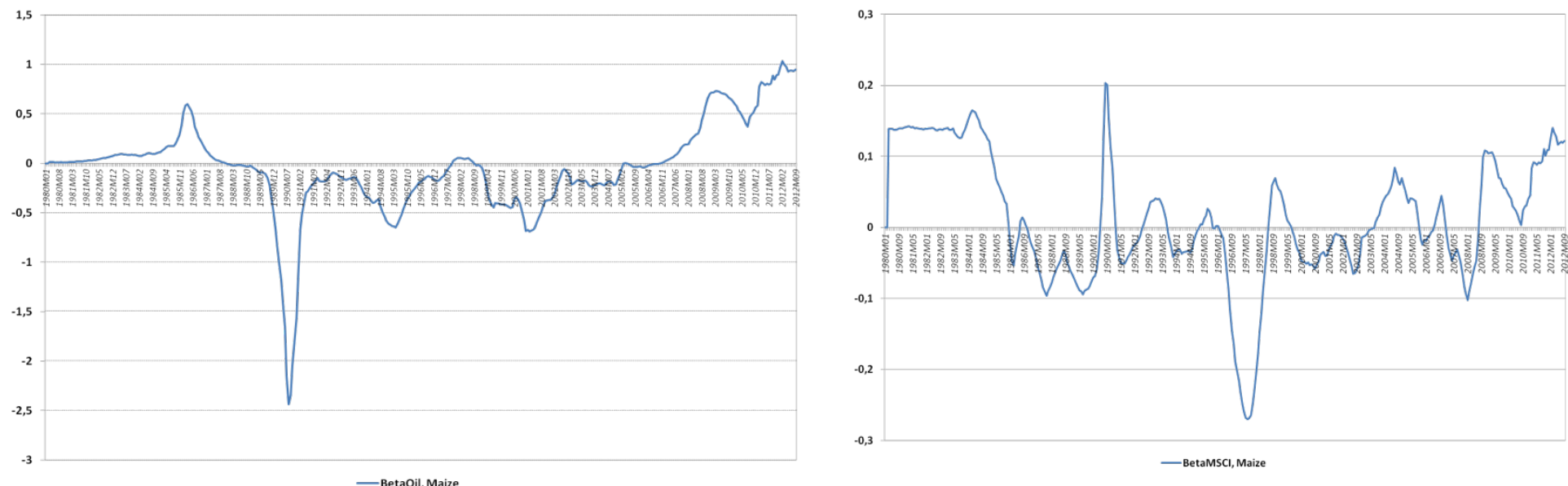

Figure 1 : Dynamic hedge ratios of the portfolio Crude oil/MSCl, Maize
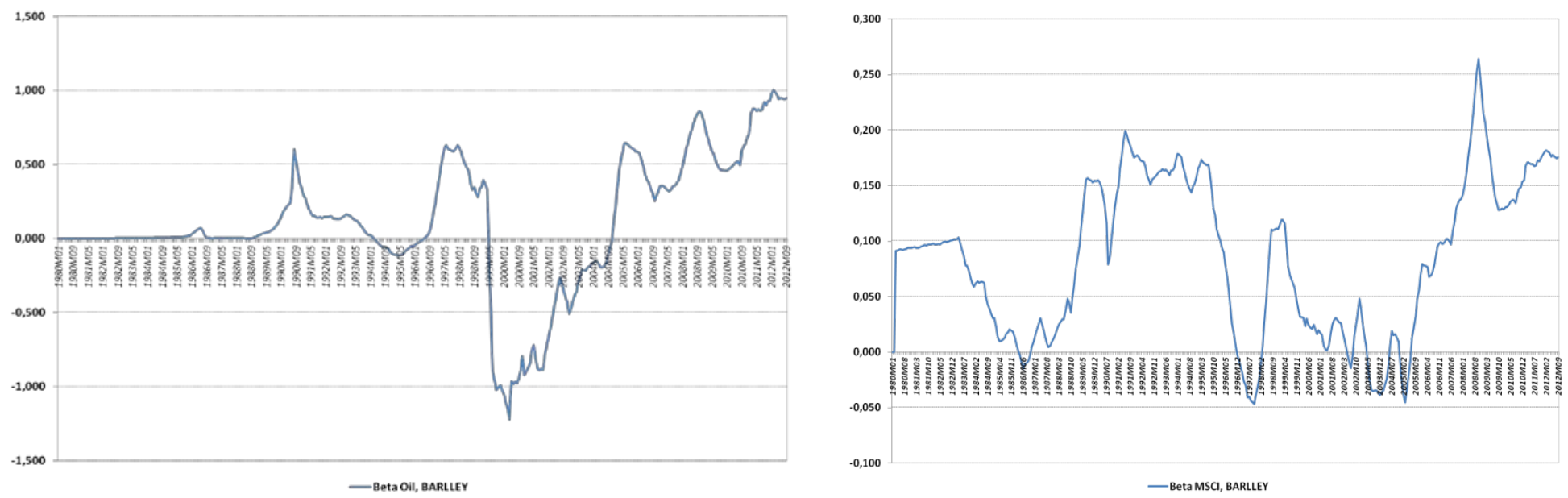

Figure 2 : Dynamic hedge ratios of the portfolio Crude oil/MSCl, Barley
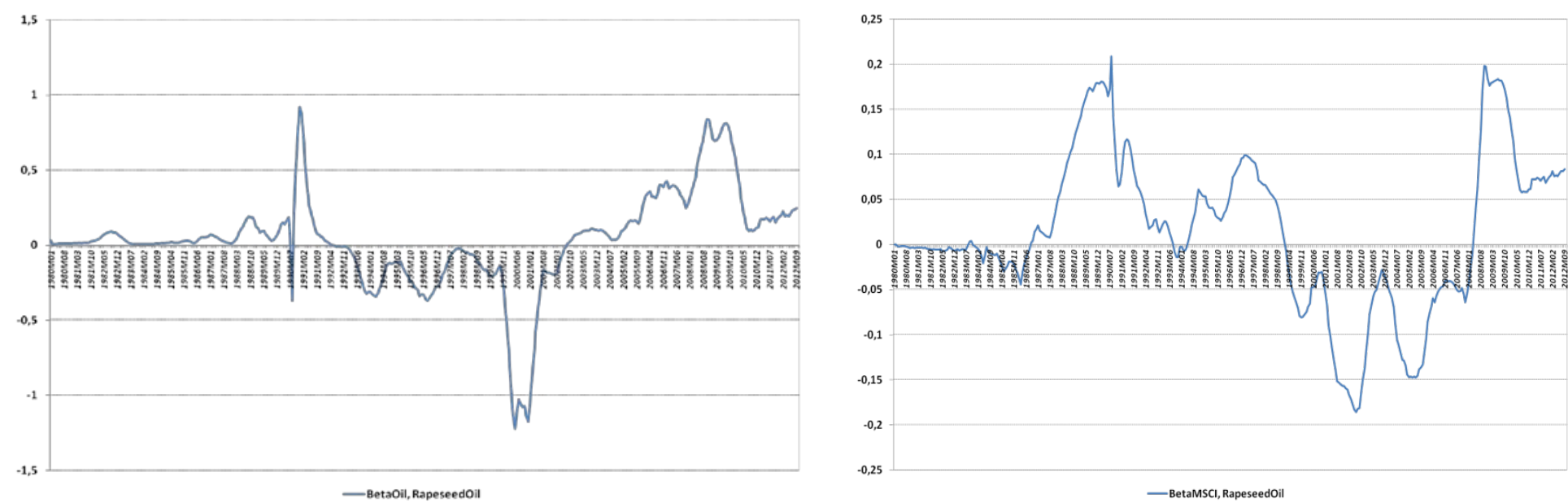

Figure 3 : Dynamic hedge ratios of the portfolio Crude oil/MSCl, Rapeseed oil 

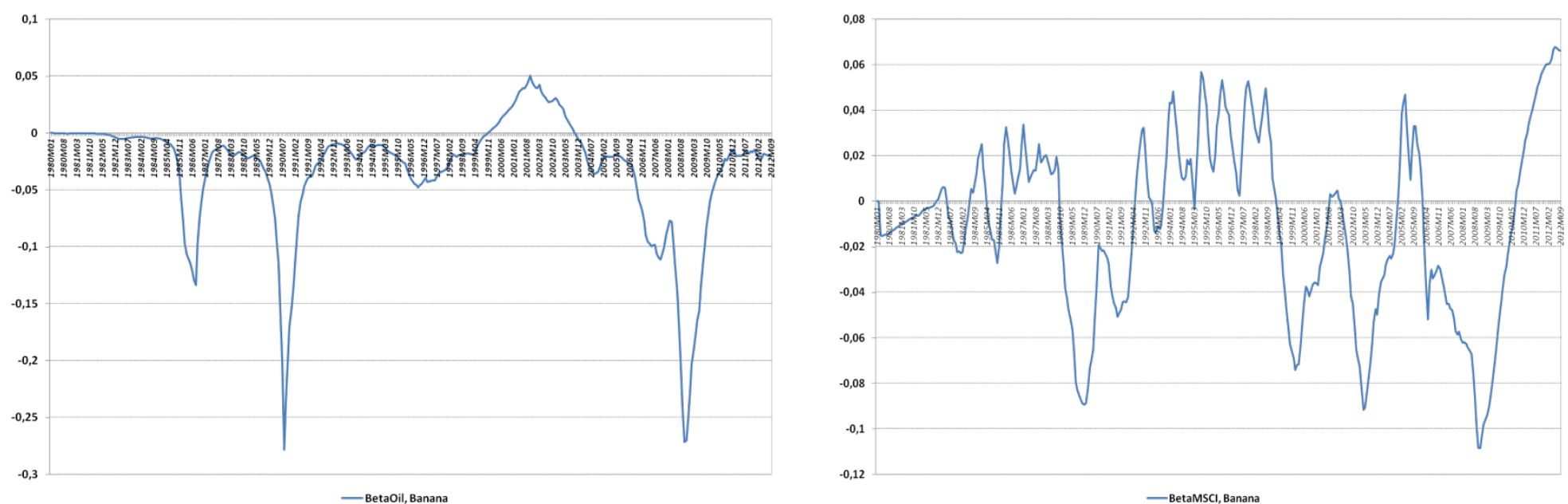

Figure 4 : Dynamic hedge ratios of the portfolio Crude oil/MSCl, Banana
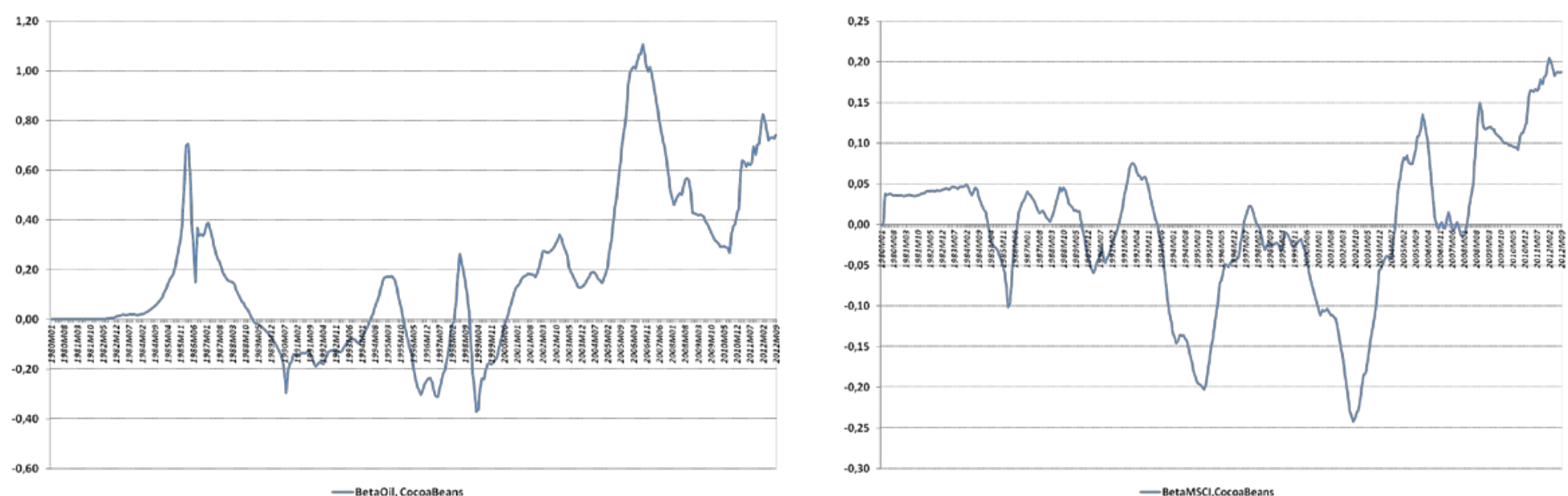

Figure 5 : Dynamic hedge ratios of the portfolio Crude oil/MSCl, Cocoa Beans
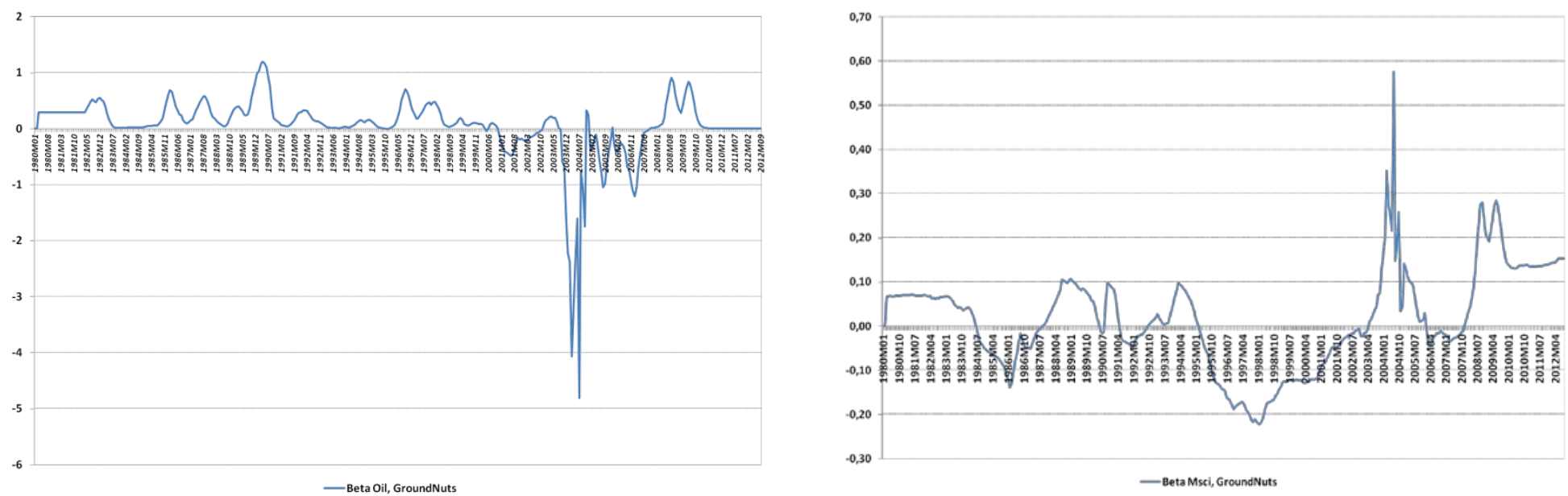

Figure 6 : Dynamic hedge ratios of the portfolio Crude oil/MSCl, Ground nuts 

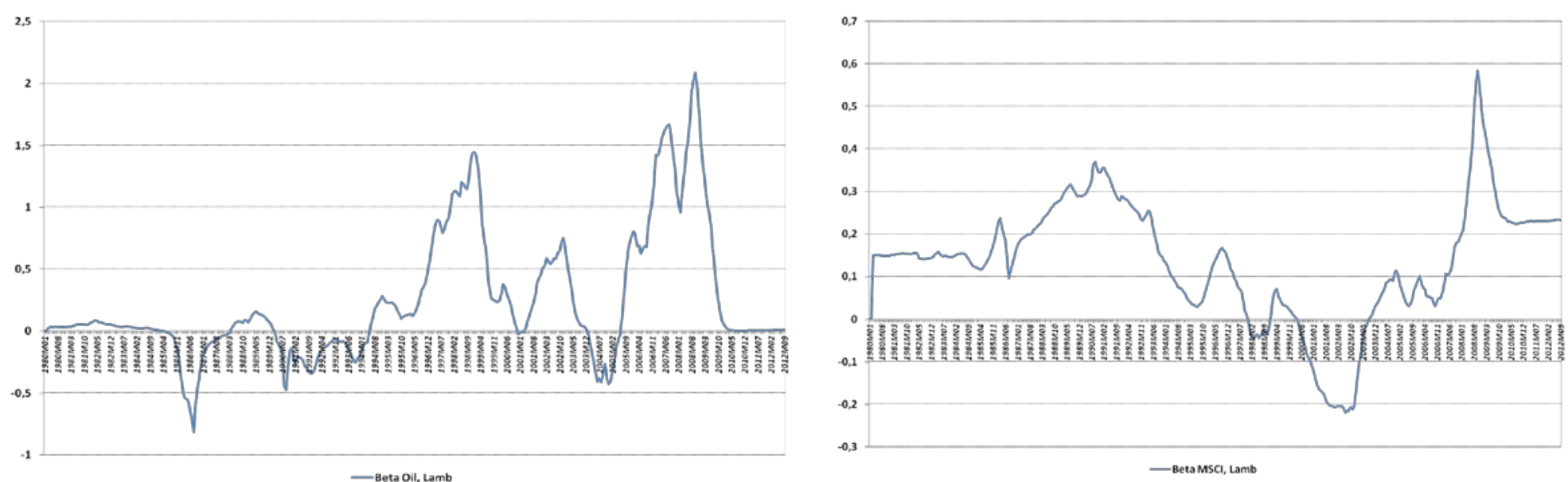

Figure 7 : Dynamic hedge ratios of the portfolio Crude oil/MSCl, Lamb
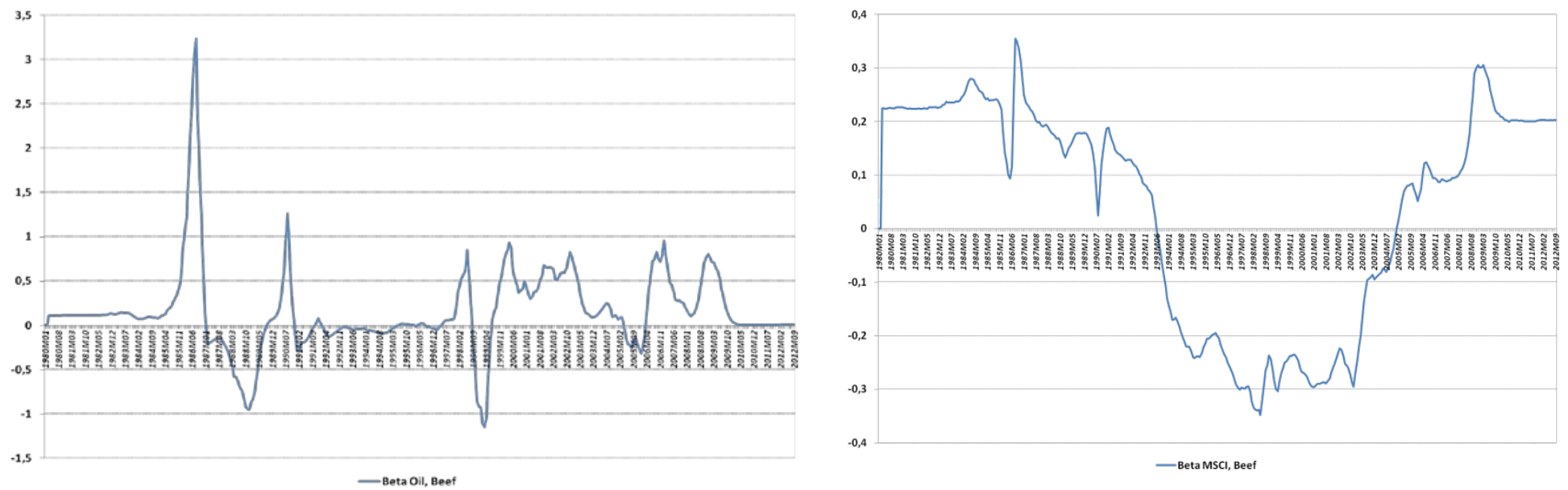

Figure 8 : Dynamic hedge ratios of the portfolio Crude oil/MSCl, Beef
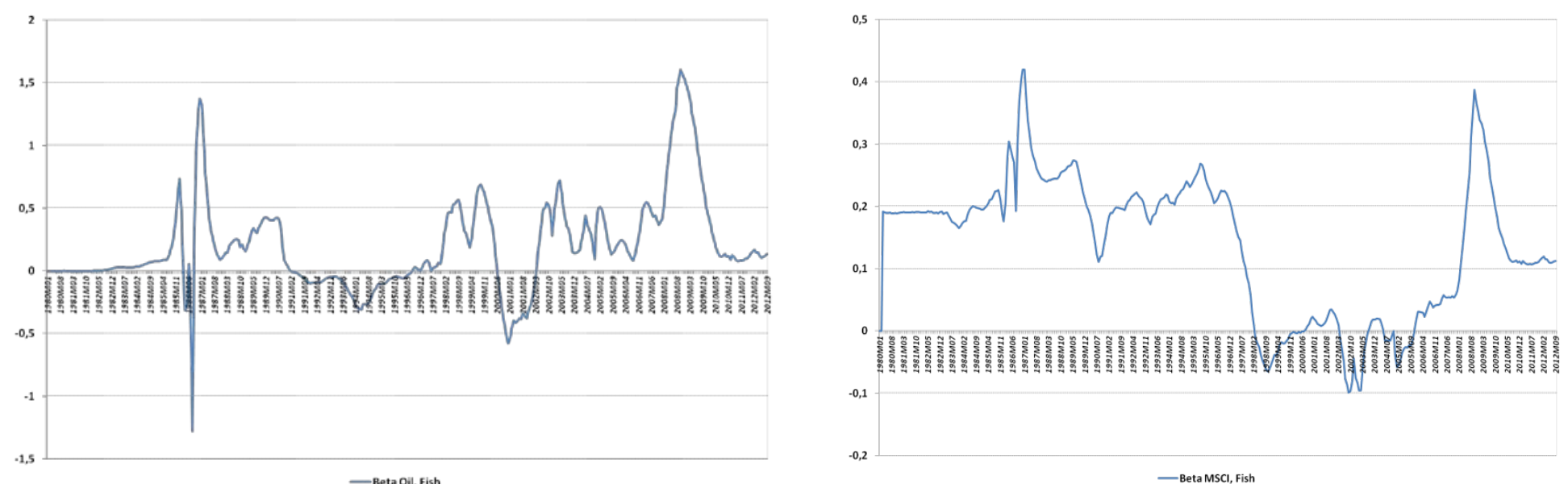

Figure 9 : Dynamic hedge ratios of the portfolio Crude oil/MSCl, Fish 